\title{
An autonomous hierarchical control for improving indoor comfort and energy efficiency of a direct expansion air conditioning system
}

\author{
Jun $\mathrm{Mei}^{\mathrm{a}}$, Xiaohua Xia ${ }^{\mathrm{a}}$, Mengjie Song ${ }^{\mathrm{b}}$ \\ ${ }^{a}$ Centre of New Energy Systems, Department of Electrical, Electronic and Computer Engineering, University of Pretoria, \\ Pretoria 0028, South Africa \\ ${ }^{b}$ Energy Research Institute at NTU (ERI@N), Research Techno Plaza, Nanyang Technological University, 50 Nanyang \\ Drive, Singapore 637553, Singapore
}

\begin{abstract}
This paper presents an autonomous hierarchical control method for a direct expansion air conditioning system. The control objective is to maintain both thermal comfort and indoor air quality at required levels while reducing energy consumption and cost. This control method consists of two layers. The upper layer is an open loop controller that allows obtaining tradeoff steady states by optimizing the energy cost of the direct expansion air conditioning system and the value of predicted mean vote under the time-of-use price structure of electricity. On the other hand, the lower layer designs a model predictive controller, which is in charge of tracking the tradeoff steady states calculated by the upper layer. Control performance of the proposed control method is compared to a conventional control strategy. The results show that the proposed control strategy reduces the energy consumption and energy cost of the direct expansion air conditioning system by $31.38 \%$ and $33.85 \%$, respectively, while maintaining both the thermal comfort and indoor air quality within acceptable ranges, which validate the proposed methodology in terms of both comfort and energy efficiency.
\end{abstract}

Keywords: Autonomous hierarchical control, PMV index, model predictive control, energy saving, time-of-use.

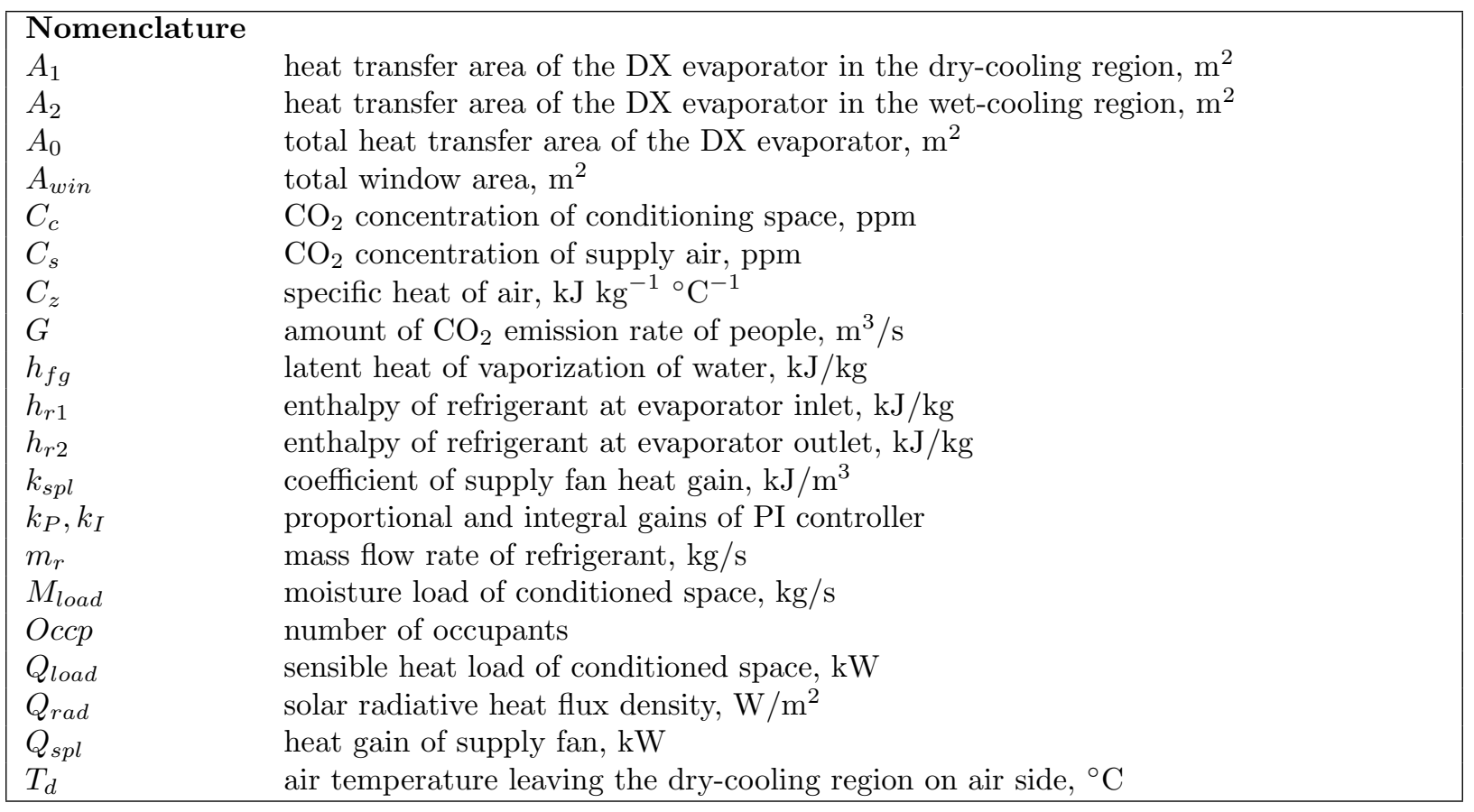




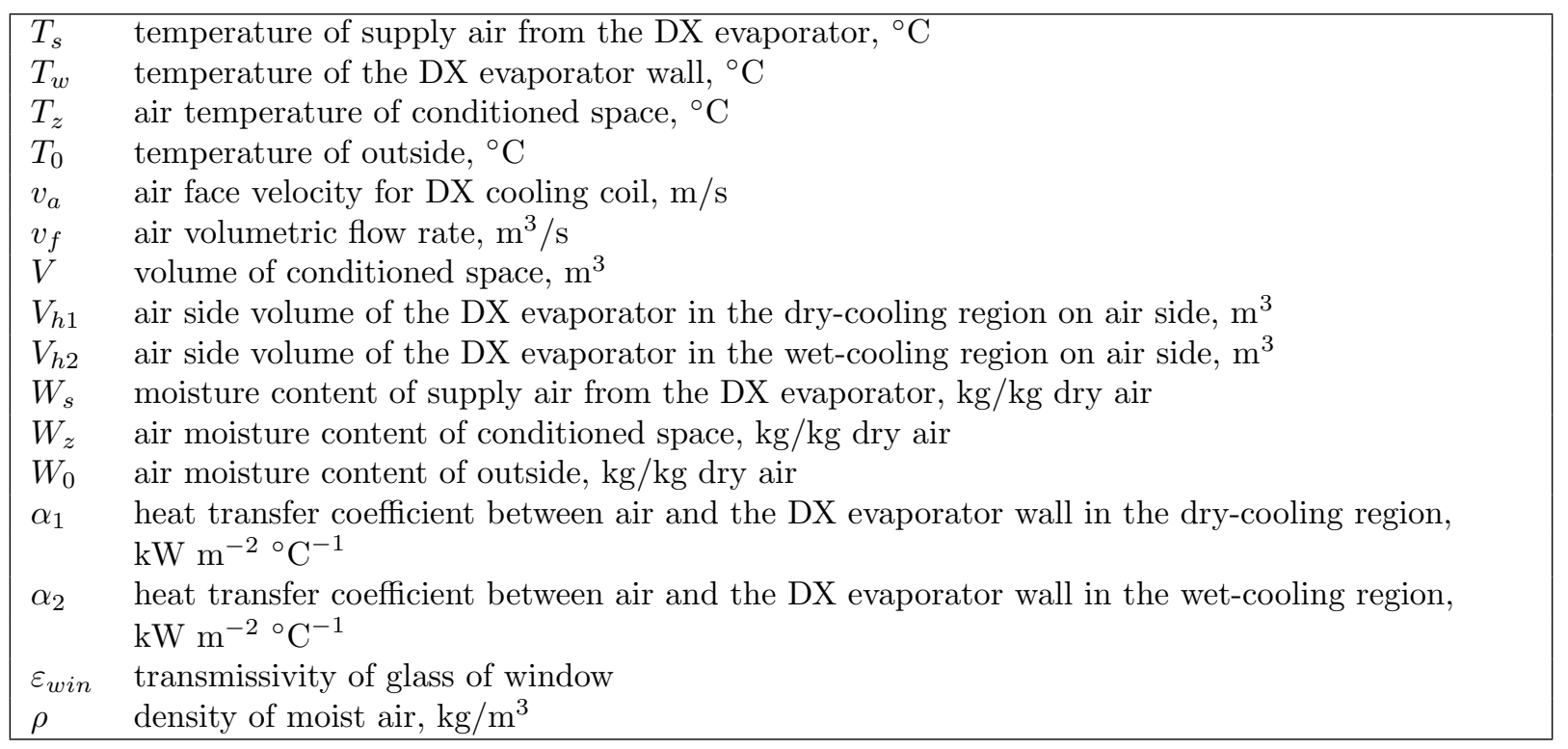

\section{Introduction}

It is well known that the building sector is responsible for almost $40 \%$ of the global total energy consumption, costing $\$ 350$ billion per year. Since energy management of building air conditioning (A/C) systems is a key factor in improving the energy efficiency and reducing the energy cost of buildings, optimal control of the A/C systems has increasingly attracted research attention. Energy efficiency improvement of buildings can also be performed at different levels of time scale and building subsystems such as ambient intelligence [1]-[3], energy balance [4]-[8], building portfolio management and planning [9]-[14] and energy-water nexus $[15,16]$.

Since people spend much time indoors, thermal comfort and indoor air quality (IAQ) are important issues in A/C control. Thermal comfort has been accomplished by regulating temperature and relative humidity of indoor air. In view of air quality, $\mathrm{CO}_{2}$ concentration is used as an indicator because carbon dioxide is the main fluid waste from occupants in a building. The indoor air temperature, humidity and $\mathrm{CO}_{2}$ concentration are affected by A/C systems, lighting, the number of occupants and natural ventilation. They are also affected by outdoor environment, including the outside temperature, humidity, $\mathrm{CO}_{2}$ concentration and solar irradiation. The A/C system needs to provide a comfortable environment for occupants with the minimum energy consumption and cost. There are strong interactions of energy cost and energy consumption with thermal comfort and IAQ. This crucial fact has been recognised by industrial and academic researchers.

Researchers proposed various control strategies to improve energy efficiency and comfort temperature [17]-[20]. In [21], the authors proposed an optimization method on room air temperature to improve both thermal comfort and energy efficiency. In [22], Cigler et al. presented an MPC to minimize the energy consumption and the value of predicted mean vote (PMV) index simultaneously. The simulation results showed that it would save 10\%-15\% energy while keeping the comfort temperature within a level defined by standards. A hierarchical control method was proposed to improve the energy efficiency while maintaining the indoor temperature equal to a value such that the PMV index will be equal to zero reported in [23]. The results showed that it would reduce more energy consumption in comparison with previous work [24]. An economic model predictive control (MPC) method for optimising the building demand and energy cost under a TOU price policy under given bounded comfort temperature is studied in [25]. It demonstrated that this strategy is capable of reducing more energy cost and shifting the peak demand to off-peak hours while keeping the temperature at comfort bounded. In [26, 27], the authors presented an MPC that minimises the expected energy cost and bounds of temperature comfort violations. One can note that all the above contributions focus on improving the energy efficiency of buildings by heating, ventilation and air conditioning (HVAC) temperature control. However, ensuring the indoor humidity at an appropriate level is also a crucial problem 
since it directly affects building occupants' thermal comfort and the operating efficiency of building A/C installations [28]. In fact, in cities with high humid climates, such as Cape Town or Hongkong, high humidity may still adversely impact indoor thermal comfort level and energy efficiency of building A/C systems even when indoor air temperature has been maintained at a desired value.

In recent years, a model-based predictive control algorithm proposed for HVAC system to control indoor temperature and humidity simultaneously taking into account energy efficiency was reported in [29]. In the study, the indoor air temperature and humidity are considered in two separate control loops. However, the control method remained inadequate fundamentally. A multi-input-multi-output (MIMO) control strategy is proposed for controlling the indoor air temperature and humidity simultaneously by varying the speeds of the compressor and the supply fan in an experimental direct expansion (DX) A/C system in [30]. In the research, the authors considered the coupling effect between indoor air temperature and humidity; so that the control accuracy and sensitivity can be improved. However, the control strategy was carried out based on the linearized system around a particular operational point, i.e., fixing the supply air temperature and moisture content. For a DX A/C system, its inlet air temperature and humidity affect its output cooling capacity directly [31]. The development of a physical model-based controller for a variable speed DX A/C system, aiming at controlling indoor air temperature and humidity simultaneously should be within its entire possible working range. An artificial neural network (ANN)-based modeling and control for an experimental variable speed DX A/C system was proposed to control the indoor air temperature and humidity simultaneously [32]. A real-time neural inverse optimal control for the simultaneous control of indoor air temperature and humidity using a DX A/C system was reported in [33]. A three-evaporator air conditioning system for simultaneous indoor air temperature and humidity control was studied in [34]. In [35], a fuzzy logic controller was developed for temperature and humidity control. The results demonstrated that the fuzzy logic controller developed can achieve the simultaneous control over indoor air temperature and humidity, with a reasonable control accuracy and sensitivity.

Nowadays, the indoor air quality (IAQ) is also an important issue for users, especially in office buildings, since a poor IAQ has a direct effect on work efficiency. In [36, 37], Zhu et. al., studied indoor air temperature, humidity and $\mathrm{CO}_{2}$ concentration control simultaneously without considering their coupling effects. However, these coupling effects cannot be ignored in many cases. In fact, the experimental investigation [38] suggested that the indoor $\mathrm{CO}_{2}$ concentration affected indoor air temperature. Furthermore, indoor humidity was correlated with $\mathrm{CO}_{2}$ concentration according to measurement results reported in [39]. Indoor air temperature, relative humidity and $\mathrm{CO}_{2}$ levels assessment in academic buildings with different HVAC systems was studied in [40]. In [41], this study aimed to establish an optimal occupant behavior that can reduce total energy consumption and improve the thermal comfort, IAQ and visual comfort simultaneously by an energy simulation and optimization tool. In [42], an energy-optimised open loop controller and a closed-loop regulation of the multi-input-multi-output (MIMO) MPC schemes for a DX A/C system were proposed to improve both thermal comfort and IAQ, while minimizing energy consumption. The results showed that the energy savings were achieved and thermal comfort and IAQ were improved. However, the setpoints of thermostats are constant over a 24-hour period. This strategy is simple but not optimal in the sense of energy efficiency or cost-effectiveness. On the other hand, the outside temperature and humidity are also constant over a 24-hour period in the study, while the outdoor air temperature and humidity vary over a 24-hour period actually. Besides, a ventilation fan with an independent pressure swing absorption box was added to improve IAQ, which would increase the complexity and the cost of hardware.

Reduction of energy consumption and cost is important to promote economic and environmental development. Therefore, it is of great interest to develop advanced control technologies for building A/C systems to reduce energy consumption and cost. However, several control methods were proposed recently to reduce energy consumption and cost of building A/C systems while maintaining thermal comfort and IAQ at required levels. In this paper, an autonomous hierarchical control method is proposed to ensure occupants' thermal comfort and IAQ in a certain environment, and at the same time, tries to reduce the energy consumption and cost for a DX A/C system. The use of the DX A/C system has many advantages. When compared to central chilled water-based A/C systems, DX A/C systems are simpler in system configuration, more energy efficient [43] and cost less to own and maintain. Therefore, DX A/C systems have been widely used over recent decades in buildings, especially in small to medium scaled buildings. The proposed control 
strategy will further enhance the performance of DX A/C system. The proposed autonomous hierarchical controller is formed by two layers. (i) The upper layer consists of a nonlinear optimizer, which provides trajectory references of indoor air temperature, humidity and $\mathrm{CO}_{2}$ concentration within acceptable ranges. This controller uses an open loop controller to optimise the energy cost of the DX A/C system and the value of the PMV index under a TOU price policy. (ii) Meanwhile, the lower layer contains a closed-loop MPC controller to track adaptively and automatically the trajectory references of indoor air temperature, humidity and $\mathrm{CO}_{2}$ concentration calculated by the upper layer. To demonstrate the advantage of the proposed control method, we will compare the proposed control and a baseline control strategy.

The contributions of this paper are listed below. The references of indoor air temperature, humidity and $\mathrm{CO}_{2}$ concentration are not needed. We present a method to autonomously and adaptively optimise and generate all steady states on required levels of thermal comfort and IAQ which could vary during the day. The volume of outside air entering into the system is fixed in [37] and [42]. In our study, the volumes of fresh air entering the DX A/C system are considered to vary with the environment over a 24-hour period and are optimised by the proposed method. Moreover, a supply fan to drive the pressure swing absorption with a built-in PI controller is proposed to reduce indoor $\mathrm{CO}_{2}$ concentration in this paper. Hence, it has the potential of reducing the complexity of computation and the cost of hardware. The PMV index is traditionally used as an indicator of indoor thermal comfort. In this study, it is used as an indicator of thermal comfort and that of IAQ when the indoor air $\mathrm{CO}_{2}$ concentration is at its steady state.

The remainder of this paper includes five parts. The nonlinear reduced order dynamical system models, the energy consumption models of the DX A/C system and the indoor cooling load models are presented in Section 2. The proposed control method is presented in Section 3. Results are given in Section 4, and conclusions are drawn in Section 5.

\section{System model}

\section{1. $D X A / C$ system}

A DX A/C system is mainly composed of two parts, which are the DX refrigeration plant (refrigerant side) and air-distribution sub-system (air side). Fig. 1 is the simplified schematic diagram of the DX A/C system. The DX refrigeration side mainly consists of the following components: a variable speed rotor compressor, an electronic expansion valve (EEV), a high-efficiency tube-louver-finned DX evaporator and an air-cooled tube-plant-finned condenser. The evaporator is placed inside the supply air duct on the air side to work as a DX air cooling coil which is located in the room. The air side includes an air-distribution ductwork with return air dampers, a variable speed centrifugal supply fan, a pressure swing absorption (PSA) box, a conditioned space and a damper position which is used to control the proportion of return air to outside air. The PSA box absorbs the $\mathrm{CO}_{2}$ contaminant concentration to maintain IAQ. The allowed fresh air is also used to improve indoor fresh air ratio.

\section{2. $D X A / C$ models}

The dynamic model of the DX A/C system is mainly derived from the principles of energy and mass balance. The model is highly nonlinear with respect to temperature, moisture content and $\mathrm{CO}_{2}$ concentration. In this paper, the system is assumed to operate in the cooling mode. The basic operation and assumptions of the system on the cooling mode are given for the purpose of simplicity as below: (i) It is assumed that p\% of outside air enters into the system and gets mixed with $(100-p) \%$ of recirculated air entering into the system. (ii) Sufficient air mixing occurs inside the heat exchangers where the air gets conditioned. (iii) Two regions on the air side of the DX evaporator are shown in Fig. 2, i.e., dry-cooling region (sensible heat transfer only) and wet-cooling region (sensible and latent heat transfer region). The coupling between both regions that the outlet air properties of the first one (dry-cooling region) are the inlet air conditions entering the wet-cooling region. Therefore, the area from zero to $A_{1}$ pertains to the dry-cooling region and the rest of the total surface area is the wet-cooling region $A_{2}$. The boundary between the dry surface and the wet surface within a DX evaporator can be determined by the distribution of the surface temperature. It is a time-varying parameter under different conditions. (iv) Thermal losses in air ducts are neglected. (v) 


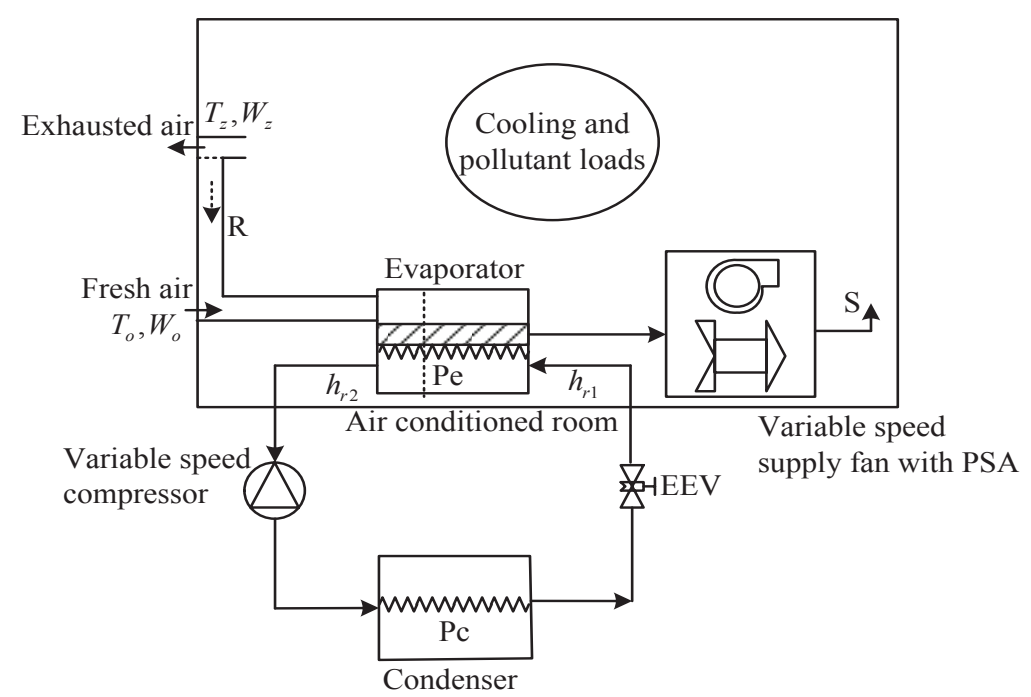

Figure 1: Simplified diagram of DX air conditioning system.

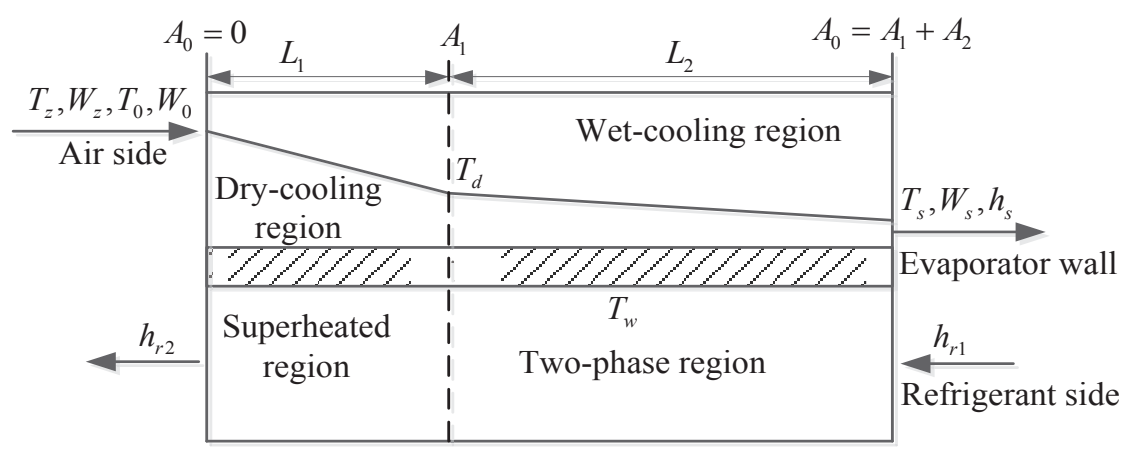

Figure 2: Simplified diagram of DX evaporator [44].

The supply air enters into the air-conditioned space to offset the cooling and pollutant loads acting upon the system. (vi) The air in the conditioned room exhausts through a fan, where $(100-p) \%$ of the air is recirculated and the rest is exhausted from the system through the fan.

Based on the above assumptions, the dynamic mathematical model for the DX A/C system for controlling indoor air temperature, moisture content and $\mathrm{CO}_{2}$ concentration is developed based on the energy and mass conservation principles, which can be described by the following equations:

$$
\begin{gathered}
C_{z} \rho V \frac{\mathrm{d} T_{z}}{\mathrm{~d} t}=C_{z} \rho v_{f}\left(T_{s}-T_{z}\right)+Q_{\text {load }}, \\
\rho V \frac{\mathrm{d} W_{z}}{\mathrm{~d} t}=\rho v_{f}\left(W_{s}-W_{z}\right)+M_{\text {load }}, \\
C_{z} \rho V_{h 1} \frac{\mathrm{d} T_{d}}{\mathrm{~d} t}=C_{z} \rho v_{f}\left((1-p \%) T_{z}+p \% T_{0}-T_{d}\right)+\alpha_{1} A_{1}\left(T_{w}-\frac{(1-p \%) T_{z}+p \% T_{0}+T_{d}}{2}\right), \\
C_{z} \rho V_{h 2} \frac{\mathrm{d} T_{s}}{\mathrm{~d} t}+\rho V_{h 2} h_{f g} \frac{\mathrm{d} W_{s}}{\mathrm{~d} t}=C_{z} \rho v_{f}\left(T_{d}-T_{s}\right)+h_{f g} \rho v_{f}\left((1-p \%) W_{z}+p \% W_{0}-W_{s}\right)+ \\
\alpha_{2} A_{2}\left(T_{w}-\frac{T_{d}+T_{s}}{2}\right),
\end{gathered}
$$




$$
\begin{gathered}
C_{w} \rho_{w} V_{w} \frac{\mathrm{d} T_{w}}{\mathrm{~d} t}=\alpha_{1} A_{1}\left(\frac{(1-p \%) T_{z}+p \% T_{0}+T_{d}}{2}-T_{w}\right)+\alpha_{2} A_{2}\left(\frac{T_{d}+T_{s}}{2}-T_{w}\right)-\left(h_{r 2}-h_{r 1}\right) m_{r}, \\
V \frac{\mathrm{d} C_{c}}{\mathrm{~d} t}=v_{s}\left(C_{s}-C_{c}\right)+C_{\text {load }} .
\end{gathered}
$$

More details for the system models (1)-(6) can be found in [42] and [44]. Note that the system models (1)-(5) without outside air entering into the system have been reported and validated by the experimental demonstrated in [44]. The model (6) has been verified in [45] by using an online learning and estimation approach for model parameter identification with acceptable accuracy.

We assume that the $\mathrm{CO}_{2}$ concentration absorption rate $v_{s}$ is a PI controller designed by

$$
v_{s}=k_{P} v_{f}+k_{I} \int_{0}^{T_{I}} v_{f} \mathrm{~d} s .
$$

The relationship among air enthalpy, temperature and the moisture content leaving the evaporator can be described by:

$$
h_{s}=C_{z} T_{s}+h_{f g} W_{s} .
$$

Then, equations (2) and (4) can be rewritten by

$$
\begin{gathered}
\rho V \frac{\mathrm{d} W_{z}}{\mathrm{~d} t}=\rho v_{f}\left(\frac{h_{s}-C_{z} T_{s}}{h_{f g}}-W_{z}\right)+M_{l o a d}, \\
\rho V_{h 2} \frac{\mathrm{d} h_{s}}{\mathrm{~d} t}=C_{z} \rho v_{f}\left(T_{d}-T_{s}\right)+h_{f g} \rho v_{f}\left((1-p \%) W_{z}+p \% W_{0}-\frac{h_{s}-C_{z} T_{s}}{h_{f g}}\right)+\alpha_{2} A_{2}\left(T_{w}-\frac{T_{d}+T_{s}}{2}\right) .
\end{gathered}
$$

The air side convective heat transfer coefficients for the louver finned evaporator under both dry-cooling and wet-cooling regions are calculated as follows [46]:

$$
\alpha_{1}=j_{e 1} \rho v_{a} \frac{C_{z}}{\operatorname{Pr}^{\frac{2}{3}}}, \alpha_{2}=j_{e 2} \rho v_{a} \frac{C_{z}}{\operatorname{Pr}^{\frac{2}{3}}},
$$

where $\operatorname{Pr}$ is Prandtl number, $j_{e 1}$ and $j_{e 2}$ are the Colburn factors. The air velocity $v_{a}$ is described as follows:

$$
v_{f}=d v_{a}+\varepsilon,
$$

where $d\left(\mathrm{~m}^{2}\right)$ is the cross-sectional area of the conditioned space, $\varepsilon$ is the error vector since the air enters or exits through the door or window.

The left-hand side of (1)-(2) is the heat flow into the conditioned space. On the right-hand side of (1), the first term denotes the heat transfer from the DX A/C system to the conditioned space, which is positive if $T_{s}>T_{z}$ for the heat mode and negative if $T_{s}<T_{z}$ for the cooling mode; the other terms mean the sensible heat load needs to be removed by the DX A/C system. Similarly, on the right-hand side of (2), the first term represents the wet-bulb temperature transferred to the conditioned space, which is positive if $W_{s}>W_{z}$ for the humidification mode and negative if $W_{s}<W_{z}$ for dehumidification mode; the second term denotes the moisture load to be removed by the DX A/C system. Eqs. (3), (5) and (10) mean that the heat transfer takes place in the inside DX A/C system. In equation (3), the first term of the right-hand side represents the heat transfer between the mixed air and the air side at the evaporator; the second term means the heat transfer between the mixed air and the evaporator wall. Eq. (6) represents a dynamic balance of indoor $\mathrm{CO}_{2}$ concentration.

Remark 1: In this paper, the relationship between the moisture content and temperature at the evaporator outlet [44], $W_{s}=\frac{0.0198 T_{s}^{2}+0.085 T_{s}+4.4984}{1000}$, has been released since it may not be feasible under different operating conditions. The proportion of outside air entering into the system is not fixed according to the changing environment during the day. In our previous work [42], we used a variable air volume (VAV) ventilation fan with an independent PSA to reduce indoor $\mathrm{CO}_{2}$ concentration. In this paper, we use the supply fan to drive the PSA with a built-in PI controller. This results in one less independent control input. 


\subsection{Load models}

Thermal comfort and IAQ are influenced by a set of disturbances, such as external air, solar radiation through opaque and transparent surfaces and internal heat gains due to appliances, lights, occupants, etc. Therefore, good performance for controlling indoor air temperature, humidity and $\mathrm{CO}_{2}$ concentration is required to deal with the disturbances. When the disturbances are neglected, a large error occurs. Nevertheless, a perfect prediction of disturbances in the future is inadequate in practice. Some disturbances can be measured, such as outside temperature, humidity and $\mathrm{CO}_{2}$ concentration, and others, such as solar radiation and internal gains, cannot but may be estimated. Next, we will provide more details on the sensible heat load $Q_{\text {load }}$, moisture load $M_{\text {load }}$, pollutant load $C_{\text {load }}$.

The indoor sensible heat load is usually related to the internal loads, including occupants, lighting, equipment, fresh air entering inside and applications and the external loads, including heat transfer conduction through the building walls, roof, floor, doors and heat transfer by radiation through fenestration such as windows and skylights. In this paper, we consider the external load including heat loads by radiation through windows and the fresh air by ventilation. The moisture load is relevant to occupants, equipment, fresh air entering inside and applications. The $\mathrm{CO}_{2}$ pollutant load is relevant to occupants' respiration. The sensible heat and moisture loads from lighting, equipment and applications are easy to identify, based on their electrical characteristics; the main uncertainties in identifying the sensible heat load and latent heat loads are from the loads associated with the occupants in the conditioned space. The sensible heat and moisture loads by occupants are determined through the current $\mathrm{CO}_{2}$ emission. To estimate the sensible heat, moisture and indoor pollutant loads, a method is proposed as follows:

$$
\begin{gathered}
Q_{\text {load }}(t)=Q_{r, \text { load }}+Q_{\text {spl }}+\mu C_{c}+\nu+Q_{\text {air }}, \\
M_{\text {load }}(t)=\phi C_{c}+\gamma+M_{\text {air }}, \\
C_{\text {load }}(t)=G \cdot \text { Occp },
\end{gathered}
$$

where $\mu$ and $\phi$ are the sensible heat and moisture gain coefficients, respectively, $\nu$ and $\gamma$ are the certainties sensible heat and moisture loads, respectively. The heat gain of the supply fan $Q_{s p l}$ increases with the air volumetric flow rate of supply air as follows:

$$
Q_{s p l}=k_{s p l} v_{f} .
$$

The external heat load by radiation $Q_{r, l o a d}$ through windows is described by the following equation:

$$
Q_{r, l o a d}=n_{w i n} \varepsilon_{w i n} A_{w i n} Q_{r a d},
$$

where $n_{\text {win }}$ denotes whether the conditioned space has a window, i.e., when $n_{\text {win }}=1$, if it has a window, while if $n_{\text {win }}=0$, it does not. The fresh air of the sensible heat load $Q_{a i r}$ and the moisture load $M_{a i r}$ in conditioned space are expressed as follows:

$$
\begin{gathered}
Q_{a i r}=p \% C_{z} \rho v_{f}\left(T_{0}-T_{z}\right), \\
M_{a i r}=p \% \rho v_{f}\left(W_{0}-W_{z}\right) .
\end{gathered}
$$

Remark 2: In this section, a simple method is given to estimate the indoor sensible heat and moisture loads, and $\mathrm{CO}_{2}$ pollutant load. An alternative method to estimate cooling load has been reported in [26]. Besides, the weather forecast data from the weather station in Cape Town are qualified for this research, because: 1) the current weather station is precisely predicted and 2) the weather conditions and solar radiation in this area are relatively stable, indicating that the profiles of the predicted outside temperature, relative humidity and $\mathrm{CO}_{2}$ concentration are representative. 


\subsection{PMV index}

The PMV index is used as a human thermal comfort requirement indicator. This indicator was first proposed by Fanger [47] to predict the average vote of a large group of persons on the thermal sensation scale. This sensation is expressed by relating the integer range $[-3,+3]$ to the qualitative words cold, cool, slightly cool, neutral, slightly warm, warm, and hot. PMV is defined by six variables, namely metabolic rate $M\left(\mathrm{~W} / \mathrm{m}^{2}\right)$, clothing insulating $I_{c l}\left(\mathrm{~m}^{2 \circ} \mathrm{C} / \mathrm{W}\right)$, air temperature $T_{z}$, air humidity $H_{z}$, air velocity $v_{a}(\mathrm{~m} / \mathrm{s})$, and mean radiant temperature $T_{r}$. The PMV index can be described by the following equation [47]:

$$
\begin{aligned}
P M V= & \left(0.303 \mathrm{e}^{-0.036 M}+0.028\right)\left\{(M-W)-3.05 \times 10^{-3}\left[5733-6.99(M-W)-P_{a}\right]-0.42[(M-\right. \\
& W)-58.15]-1.7 \times 10^{-5} M\left(5867-P_{a}\right)-0.0014 M\left(34-T_{z}\right)-3.96 \times 10^{-8} f_{c l}\left[\left(T_{c l}+273\right)^{4}\right. \\
& \left.\left.-\left(T_{r}+273\right)^{4}\right]-f_{c l} h_{c} \cdot\left(T_{c l}-T_{z}\right)\right\},
\end{aligned}
$$

where $W\left(\mathrm{~W} / \mathrm{m}^{2}\right)$ is the external work; $P_{a}$ is the partial water vapor pressure in Pascal. The surface temperature of clothing $T_{c l}$ is given by:

$$
T_{c l}=35.7-0.028(M-W)-I_{c l}\left\{3.96 \times 10^{-8} f_{c l}\left[\left(T_{c l}+273\right)^{4}-\left(T_{r}+273\right)^{4}\right]+f_{c l} h_{c}\left(T_{c l}-T_{z}\right)\right\},
$$

and the convective heat transfer coefficient $h_{c}$ is defined as:

$$
h_{c}= \begin{cases}h_{c}^{*}, & \text { if } h_{c}^{*}>12.1 \sqrt{v_{a}}, \\ 12.1 \sqrt{v_{a}}, & \text { if } h_{c}^{*}<12.1 \sqrt{v_{a}},\end{cases}
$$

where $h_{c}^{*}=2.38 \cdot\left(T_{c l}-T_{z}\right)^{0.25}, f_{c l}$ is the ratio of body surface area covered by clothes to the naked surface area, can be defined as:

$$
f_{c l}= \begin{cases}1.00+1.290 I_{c l} & \text { if } I_{c l} \leq 0.078 \\ 1.05+0.645 I_{c l} & \text { if } I_{c l}>0.078\end{cases}
$$

The mean radiant temperature $T_{r}$ is determined as [48]:

$$
T_{r}=\left[\left(T_{g}+273\right)^{4}+\frac{1.10 \times 10^{8} v_{a}^{0.6}}{\epsilon D^{0.4}}\left(T_{g}-T_{z}\right)\right]^{1 / 4}-273,
$$

where $T_{g}$ is the globe temperature; $D$ and $\epsilon$ are the globe diameter in meters and the globe emissivity coefficient, respectively. $P_{a}$ is related to the relative humidity of the air $H_{z}$ by means of Antoine's equation [49]:

$$
P_{a}=10 H_{z} \mathrm{e}^{\left(16.6536-4030.183 /\left(T_{z}+235\right)\right)},
$$

where $H_{z}=100 W_{z} / A_{\text {conv }}, A_{\text {conv }}$ is the unit transfer coefficient. The metabolic rate $M$ is determined by [50]:

$$
M=\lambda G,
$$

where the coefficient $\lambda$ is a constant. Then the metabolic rate $M$ under a steady state of the indoor $\mathrm{CO}_{2}$ concentration can be rewritten as follows:

$$
M=\frac{\lambda}{O c c p}\left(k_{P} v_{f}+k_{I} \int_{0}^{T_{I}} v_{f} d s\right)\left(C_{c}-C_{s}\right) .
$$

The PMV can be written as a function of the following variables:

$$
\mathrm{PMV}=g\left(T_{z}, W_{z}, C_{c}, v_{f}, T_{r}, I_{c l}, T_{c l}\right) .
$$

Remark 3: There are several existing metrics to measure human (dis)comfort, e.g., temperature constraint violations [26], comfort penalty [17], predicted percentage dissatisfied (PPD) [51], and PMV index $[23,29]$. The PMV index has been used as an indicator to maintain indoor comfort temperature [23] and to control indoor temperature and humidity [29]. In this paper, the equation (22) implies that the modified PMV index can estimate not only the indoor thermal comfort but also IAQ under a steady state of the indoor $\mathrm{CO}_{2}$ concentration and keep them in a certain range. This is subjective and can be considered as perfect when $\mathrm{PMV}=0$. 


\subsection{Energy models for the $D X A / C$ system}

The DX A/C system components that consume energy include the power input of the evaporator fan, compressor fan, and condenser. The power to drive the dampers is assumed to be negligible. The total power consumption $P_{t o t}$ of the DX A/C system at time $t$ then is calculated as [52]:

$$
P_{\text {tot }}=P_{e}+P_{c}+P_{f},
$$

where the fan power input of the evaporator $P_{e}$, the fan power of the compressor $P_{f}$ and the power input of the condenser $P_{c}$ are given below:

$$
\begin{gathered}
P_{e}=a_{0}+a_{1} v_{f},+a_{2} v_{f}^{2}+a_{3} T_{s}+a_{4} T_{s}^{2}+a_{5} Q_{c}+a_{6} Q_{c}^{2}+a_{7} v_{f} T_{s}+a_{8} v_{f} Q_{c}+a_{9} T_{s} Q_{c}, \\
P_{f}=b_{0}+b_{1} T_{d}+b_{2} T_{s}+b_{3} T_{d}^{2}+b_{4} T_{d} T_{s}+b_{5} T_{s}^{2}+b_{6} T_{d}^{3}+b_{7} T_{d}^{2} T_{s}+b_{8} T_{d} T_{s}^{2}+b_{9} T_{s}^{3}, \\
P_{c}=c_{0}+c_{1} m_{r}+c_{2} m_{r}^{2},
\end{gathered}
$$

where the coefficients $a_{i}(i=0,1, \ldots, 9), b_{i}(i=0,1, \ldots, 9), c_{i}(i=0,1,2)$ are constant and can be determined by curve-fitting of experimental data in [52]. The indoor cooling load $Q_{c}$ is the summation of the sensible and latent heat loads.

\subsection{Constraints}

The DX A/C system is subject to thermal comfort, IAQ and operational constraints defined as below.

(C1) PMV $\in[\underline{\mathrm{PMV}}, \overline{\mathrm{PMV}}]$. The limit of the PMV value means thermal comfort and IAQ are within the required levels for human.

(C2) $T_{z} \in\left[\underline{T}_{z}, \bar{T}_{z}\right], W_{z} \in\left[\underline{W}_{z}, \bar{W}_{z}\right], C_{c} \in\left[\underline{C}_{c}, \bar{C}_{c}\right]$. The indoor air temperature, moisture content and $\mathrm{CO}_{2}$ concentration are within the required ranges for occupants in the conditioned space.

(C3) $T_{s} \in\left[\underline{T}_{s}, \bar{T}_{s}\right], W_{s} \in\left[\underline{W}_{s}, \bar{W}_{s}\right]$. The bounds of the supply air temperature and moisture content are constrained because of the physical characteristics of the coils and the air cooling coils inside the evaporator. Besides, the upper bounds $\bar{T}_{s}$ and $\bar{W}_{s}$ are less than $T_{z}$ and $W_{z}$, respectively, since the DX A/C system is operating in the cooling mode. The bound of air enthalpy $h_{s}$ satisfies: $h_{s} \in\left[C_{z} \underline{T}_{s}+h_{f g} \underline{W}_{s}, C_{z} \bar{T}_{s}+h_{f g} \bar{W}_{s}\right]$ due to $(8)$.

(C4) $T_{w} \leq T_{d}$. The air temperature after the surface of the DX cooling coil cannot be warm.

(C5) $v_{f} \in\left[\underline{v}_{f}, \bar{v}_{f}\right], m_{r} \in\left[\underline{m}_{r}, \bar{m}_{r}\right]$. The upper bounds of the air volumetric flow rate $\bar{v}_{f}$ and mass flow rate of refrigerant $\bar{m}_{r}$ are limited by the physical characteristics of the DX A/C system. The lower bounds $\underline{v}_{f}>0$ and $\underline{m}_{r}>0$ match minimum operation and ventilation demands.

(C6) $p \% \in[p \%, \bar{p} \%)$. The upper and lower bounds limit the ratio of the fresh air entering indoor.

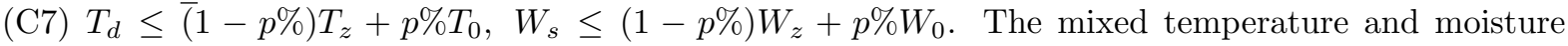
content between the fresh air and return air after the DX dry-cooling region and wet-cooling region can only decrease, respectively.

By collecting the system dynamic equations (1), (3), (5)-(6) and (9)-(10), we reach the following:

$$
\dot{x}(t)=f(x(t), u(t), w(t)),
$$

where the state vector of the system is denoted by

$$
x=\left[h_{s}, T_{z}, T_{d}, T_{w}, W_{z}, C_{c}\right]^{T},
$$

the control vector is denoted by

$$
u=\left[v_{f}, m_{r}\right]^{T},
$$

the load vector is denoted by

$$
w=\left[Q_{\text {load }}, M_{\text {load }}, C_{\text {load }}\right]^{T},
$$


the output vector is denoted by

$$
y=\left[T_{z}, W_{z}, C_{c}\right]^{T} .
$$

The constraints in (C1)-(C7) are compactly written as

$$
x \in \mathbb{X}, u \in \mathbb{U}, P M V \in \mathbb{F}, p \in \mathbb{P}, T_{s} \in \mathbb{T}_{s}, W_{s} \in \mathbb{W}_{s}, \text { and } h(x) \leq 0,
$$

where $\mathbb{X}, \mathbb{U}, \mathbb{P}, \mathbb{T}_{s}$ and $\mathbb{W}_{s}$ are bounded sets, and $h(x)$ is a function of state variables.

\subsection{TOU Strategy}

In this paper, the energy charge is determined based on the TOU strategy. The TOU electricity tariff is a typical program of demand-side management, in which the electricity price changes over different periods based on the electricity supply cost; for example, a high price $\sigma_{h}$ for peak periods $\mathcal{T}_{h}$, medium price $\sigma_{m}$ for standard periods $\mathcal{T}_{m}$ and low price $\sigma_{l}$ for off-peak periods $\mathcal{T}_{l}$. In this study, the daily TOU electricity price can be described as

$$
\sigma(l)=\left\{\begin{array}{l}
\sigma_{h}=0.20538 \$ / \mathrm{kW} \mathrm{h}, l \in \mathcal{T}_{h} \\
\sigma_{m}=0.05948 \$ / \mathrm{kW} \mathrm{h}, l \in \mathcal{T}_{m} \\
\sigma_{l}=0.03558 \$ / \mathrm{kW} \mathrm{h}, l \in \mathcal{T}_{l}
\end{array}\right.
$$

where $\mathcal{T}_{h}=(8,11] \bigcup(19,21], \mathcal{T}_{l}=(0,7] \bigcup(23,24]$ and $\mathcal{T}_{m}=(7,8] \cup(11,19] \cup(21,23] . \$$ is the United States dollar and time $\mathcal{T}$ is the whole period of the day with $l=1, \ldots, 24$. Since there is a big difference in energy prices between the peak and off-peak hours, cost savings can be expected if significant amount of peak power consumption is shifted to off-peak hours. To minimize the energy cost, some previous optimization control strategies are reported in $[18,25]$. In this paper, we propose an alternative optimisation control scheme to minimize not only the energy cost but also the energy consumption.

\section{Hierarchical control}

Hierarchical control can be interpreted as an attempt to handle complex problems by decomposing them into smaller subproblems and reassembling their solutions in a hierarchical structure. The idea is to establish a hierarchical control structure composed of two layers. The two layers are adopted by using a control schedule, the simplified scheme of which is described in Fig. 3. The main principle of hierarchical control is as follows. At the upper layer, the objective is performed to compute the optimal conditions with respect to a performance index representing an economic and environmental criterion over a long-term scale horizon $H_{L}$ with a sampling period $T_{L}$. At this stage, a detailed, a physical nonlinear model of the system although static is used. At the lower layer, a simple linear dynamic model is used to design an MPC controller, guaranteeing that the target values transmitted from the upper layer are obtained over a short time horizon $h_{l}=T_{L}$ with a smaller sampling period $t_{l}=T_{L} / n_{l}$. Fig. 3 implies that the upper layer sends information to the lower layer at the sampling instant $m T_{L}(m=0,1, \ldots, \infty)$; meanwhile, the lower layer receives the information as a task, and then completes the task within the sampling intervals $\left[m T_{L}+q t_{l}, m T_{L}+(q+1) t_{l}\right)\left(q=0,1, \ldots, n_{l}-1\right)$.

This paper presents an autonomous hierarchical control approach to obtain a real-time optimisation scheduling strategy for the DX A/C system to minimise the total energy cost while maintaining the indoor thermal comfort and IAQ within acceptable ranges. The control method is based on a traditional control scheme with a reference governor in the upper layer, named the optimization layer, which, by means of a nonlinear optimizer, is able to generate the steady states and the optimal volume of air entering the system by optimising the energy cost of the DX A/C system and the value of the PMV index under the TOU strategy. Then, the lower layer receives the steady states as input, and the closed-loop MPC controller is designed to track the trajectory references of indoor air temperature, moisture content and $\mathrm{CO}_{2}$ concentration. The conceptual framework of the proposed autonomous hierarchical control approach is shown in Fig. 4 . The details are provided in the following subsections. 


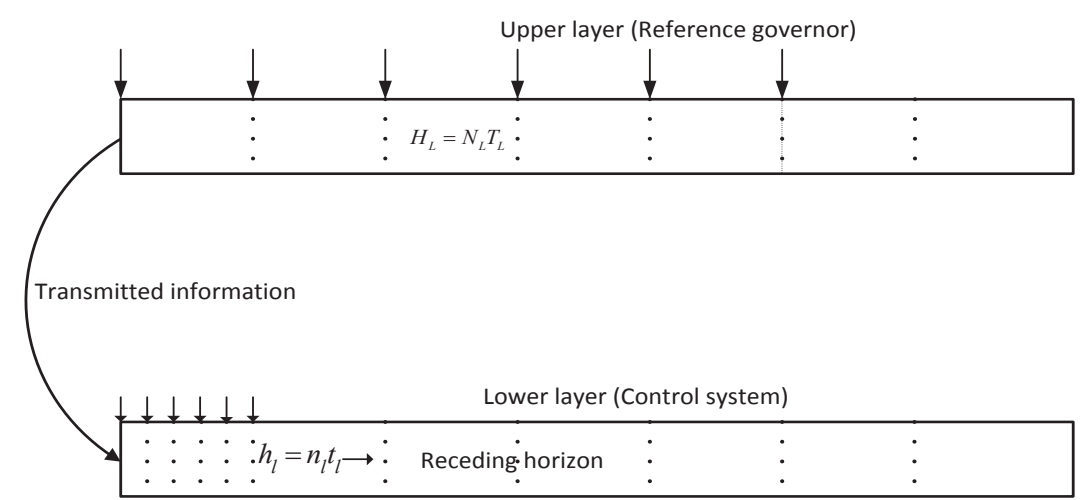

Figure 3: Simplified schematic of two-layer hierarchical structure scheme.

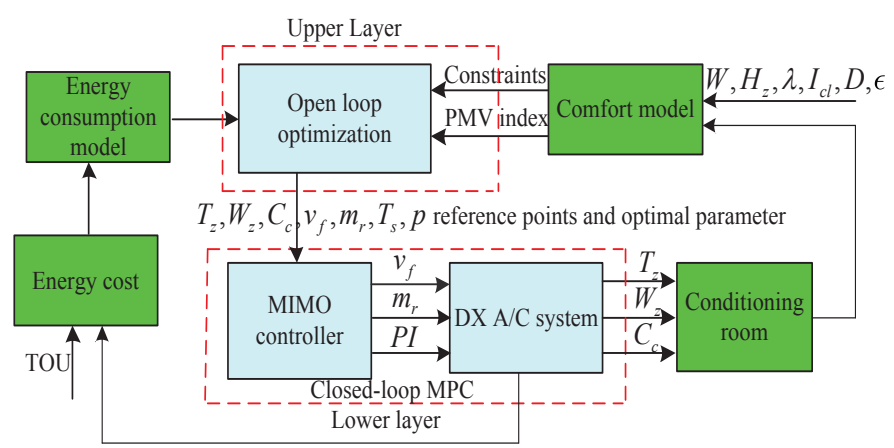

Figure 4: Conceptual framework of the proposed hierarchical control approach.

\subsection{Optimization layer (Upper layer)}

At the upper layer, the reference governor has been defined according to the optimization problem described by (30). Note that the PMV index (22) and the energy consumption model (23) are the optimization objectives. At the upper layer, the optimisation problem is considered as an open loop optimal control framework. Considering the DX A/C system (27) and its constraints (28), we formulate the following optimal controller to generate the steady states.

$$
\min \left(\alpha\left|P M V\left(t_{m_{0}}\right)\right|+(1-\alpha) P_{t o t}\left(t_{m_{0}}\right) \sigma\left(t_{m_{0}}\right)\right)
$$

subject to the following constraints:

$$
\begin{gathered}
f\left(x\left(t_{m_{0}}\right), u\left(t_{m_{0}}\right), T_{s}\left(t_{m_{0}}\right), p\left(t_{m_{0}}\right)\right)=0 \\
x\left(t_{m_{0}}\right) \in \mathbb{X}, u\left(t_{m_{0}}\right) \in \mathbb{U}, P M V\left(t_{m_{0}}\right) \in \mathbb{F}, p\left(t_{m_{0}}\right) \in \mathbb{P}, T_{s}\left(t_{m_{0}}\right) \in \mathbb{T}_{s}, W_{s}\left(t_{m_{0}}\right) \in \mathbb{W}_{s}, h\left(x\left(t_{m_{0}}\right)\right) \leq 0,
\end{gathered}
$$

where $\alpha$ is a weighting factor $(0<\alpha<1), x, u$ and $f(\cdot)$ are denoted in $(27) . x\left(t_{m_{0}}\right), u\left(t_{m_{0}}\right), v\left(t_{m_{0}}\right)$ are the optimization variables for $m=0, \ldots, N_{L}-1$, where $v=\left[p, T_{s}, T_{r}, T_{c l}\right]$.

Assuming that all the variables are within the bounded sets, feasible solutions exist for the optimization problem (30) by using an open loop controller. Among all the feasible solutions, let $x_{s}\left(t_{m_{0}}\right), u_{s}\left(t_{m_{0}}\right), v_{s}\left(t_{m_{0}}\right)$ be the optimal solution of optimization problem (30), and $x_{s}\left(t_{m_{0}}\right) \in \boldsymbol{X}_{s}, u_{s}\left(t_{m_{0}}\right) \in \boldsymbol{U}_{s}, v_{s}\left(t_{m_{0}}\right) \in \boldsymbol{V}_{s}$ for $m=0, \ldots, N_{L}-1 . \boldsymbol{X}_{s}, \boldsymbol{U}_{s}, \boldsymbol{V}_{s}$ are the optimal sequence points of the state, input and parameter variables. In this paper, the optimal sequence points are the steady states of equation (31).

Remark 4: The weighting factor $\alpha$ is chosen to balance the tradeoff between the two objectives, which are energy cost and comfort levels. Specifically, a relative large $\alpha$ gives better comfort level but worse cost savings. In the case that $\alpha$ is relatively large, more effort is put into optimizing the most comfortable indoor 
air temperature, humidity and $\mathrm{CO}_{2}$, which may result in a loss of balancing capacity. The parameter $\alpha$ can be adjusted by utilities to achieve different goals.

The above nonlinear steady state optimization algorithm is provided as below.

Algorithm 1. Nonlinear Programming algorithm to the DX A/C system static optimization problem.

Initialization: Given initial state values $x(0)$ and $u(0)$. The initial state values are selected within their bounds.

1: Input the data of the outside temperature, relative humidity, sensible heat load, latent heat load and pollutant load.

2: The objective function (30) and constraints in (31) and (32) are converted into the following standard nonlinear programming so that it can be conveniently solved by the Matlab built-in function fmincon:

$$
\min f_{c}^{T} \cdot z \quad \text { s.t. } \quad\left\{\begin{array}{l}
c(z) \leq 0 \\
c e q(z)=0 \\
A \cdot z \leq b \\
A_{e q} \cdot z=b e q \\
l b \leq z \leq u b
\end{array}\right.
$$

3: Solve the above procedure (33).

\subsection{Control layer (Lower layer)}

As discussed above, for each every sample period $T_{L}$, the upper layer controller computes the optimal steady state point and delivers it into the lower layer. The task of the lower layer receives the steady state as the trajectory reference and includes a control algorithm trying to drive the system to track the trajectory reference. Therefore, in this case, this layer consists of a discrete-time MPC controller with a sampling time of $t_{m_{q}} \in\left[m T_{L}+q t_{l}, M T_{L}+(q+1) t_{l}\right), m=0,1, \ldots, N_{L}-1, q=0,1, \ldots, t_{l}-1$, which is designed to track the reference point of indoor air temperature, moisture content and $\mathrm{CO}_{2}$ concentration.

In the sequel, we make a commensurate quantization assumption: all variables are quantised in the two sampling schemes, i.e., they are represented by the starting values and remain these values in the same sampling interval, and the objective functions $P M V(t), P_{t o t}(t)$, the TOU function $\sigma(t)$, and the constraints in (C1)-(C7) are coarsely quantised, i.e., they take their corresponding values at $m T_{L}$, for all $t \in\left[m T_{L},(m+1) T_{L}\right)$. This assumption ensures that if the steady state $\left(x_{s}\left(t_{m_{q}}\right), u_{s}\left(t_{m_{q}}\right)\right)$ would be obtained from the optimisation (30)-(32), then one would have $\left(x_{s}\left(t_{m_{q}}\right), u_{s}\left(t_{m_{q}}\right)\right)=\left(x_{s}\left(t_{m_{0}}\right), u_{s}\left(t_{m_{0}}\right)\right)$.

The lower layer receives the reference points of state vector and input vector, which are defined as $x_{s}\left(t_{m_{q}}\right) \triangleq\left[h_{s, s}\left(t_{m_{q}}\right), T_{z, s}\left(t_{m_{q}}\right), T_{d, s}\left(t_{m_{q}}\right), T_{w, s}\left(t_{m_{q}}\right), W_{z, s}\left(t_{m_{q}}\right), C_{c, s}\left(t_{m_{q}}\right)\right]^{T}$ and $u_{s}\left(t_{m_{q}}\right)=\left[v_{f, s}\left(t_{m_{q}}\right)\right.$, $\left.m_{r, s}\left(t_{m_{q}}\right)\right]^{T}$. Define $\delta T_{z}\left(t_{m_{q}}\right)=T_{z}\left(t_{m_{q}}\right)-T_{z, s}\left(t_{m_{q}}\right), \delta W_{z}\left(t_{m_{q}}\right)=W_{z}\left(t_{m_{q}}\right)-W_{z, s}\left(t_{m_{q}}\right), \delta C_{c}\left(t_{m_{q}}\right)=C_{c}\left(t_{m_{q}}\right)-$ $C_{c, s}\left(t_{m_{q}}\right), \delta h_{s}\left(t_{m_{q}}\right)=h_{s}\left(t_{m_{q}}\right)-h_{s, s}\left(t_{m_{q}}\right), \delta T_{d}\left(t_{m_{q}}\right)=T_{d}\left(t_{m_{q}}\right)-T_{d, s}\left(t_{m_{q}}\right), \delta T_{w}\left(t_{m_{q}}\right)=T_{w}\left(t_{m_{q}}\right)-T_{w, s}\left(t_{m_{q}}\right)$, $\delta v_{f}\left(t_{m_{q}}\right)=v_{f}\left(t_{m_{q}}\right)-v_{f, s}\left(t_{m_{q}}\right), \delta m_{r}\left(t_{m_{q}}\right)=m_{r}\left(t_{m_{q}}\right)-m_{r, s}\left(t_{m_{q}}\right)$, as the deviations of states and inputs from their trajectory references at sampling period $\left[m T_{L}+q t_{l}, m T_{L}+(q+1) t_{l}\right)$. Therefore, the dynamical mathematical equation of the DX A/C system at time $t_{m_{q}}$ can be linearized and written in a linear statespace representation:

$$
\left\{\begin{array}{l}
\delta \dot{x}\left(t_{m_{q}}\right)=A_{c}\left(x_{s}\left(t_{m_{0}}\right), u_{s}\left(t_{m_{0}}\right)\right) \delta x\left(t_{m_{q}}\right)+B_{c}\left(x_{s}\left(t_{m_{0}}\right), u_{s}\left(t_{m_{0}}\right)\right) \delta u\left(t_{m_{q}}\right), \\
y\left(t_{m_{q}}\right)=C \delta x\left(t_{m_{q}}\right)+y_{s}\left(t_{m_{0}}\right)
\end{array}\right.
$$

where the state variables $\delta x\left(t_{m_{q}}\right)=x\left(t_{m_{q}}\right)-x_{s}\left(t_{m_{0}}\right)=\left[\delta h_{s}\left(t_{m_{q}}\right), \delta T_{z}\left(t_{m_{q}}\right), \delta T_{d}\left(t_{m_{q}}\right), \delta T_{w}\left(t_{m_{q}}\right), \delta W_{z}\left(t_{m_{q}}\right)\right.$, $\left.\delta C_{c}\left(t_{m_{q}}\right)\right]^{T}$, the input variables $\delta u\left(t_{m_{q}}\right)=u\left(t_{m_{q}}\right)-u_{s}\left(t_{m_{q}}\right)=\left[\delta v_{f}\left(t_{m_{q}}\right), \delta m_{r}\left(t_{m_{q}}\right)\right]^{T}, y_{s}\left(t_{m_{0}}\right)=\left[T_{z, s}\left(t_{m_{0}}\right)\right.$, $\left.W_{z}\left(t_{m_{0}}\right), C_{c, s}\left(t_{m_{0}}\right)\right]^{T}$ and $y\left(t_{m_{q}}\right)=\left[T_{z}\left(t_{m_{q}}\right), W_{z, s}\left(t_{m_{q}}\right), C_{c}\left(t_{m_{q}}\right)\right]^{T}$ are the original output variables.

$A\left(x_{s}\left(t_{m_{0}}\right), u_{s}\left(t_{m_{0}}\right)\right), B\left(x_{s}\left(t_{m_{0}}\right), u_{s}\left(t_{m_{0}}\right)\right), C$ are the system state matrix, input matrix and output matrix 
at the sampling time $t_{m_{q}}$, respectively, which can be calculated by:

$$
A_{c}\left(x_{s}\left(t_{m_{0}}\right), u_{s}\left(t_{m_{0}}\right)\right)=\frac{\partial f\left(x\left(t_{m_{0}}\right), u\left(t_{m_{0}}\right)\right)}{\partial x\left(t_{m_{0}}\right)} \mid \begin{aligned}
& x\left(t_{m_{0}}\right)=x_{s}\left(t_{m_{0}}\right) \\
& u\left(t_{m_{0}}\right)=u_{s}\left(t_{m_{0}}\right)
\end{aligned},
$$

and

$$
C=\left[\begin{array}{llllll}
0 & 1 & 0 & 0 & 0 & 0 \\
0 & 0 & 0 & 0 & 1 & 0 \\
0 & 0 & 0 & 0 & 0 & 1
\end{array}\right]
$$

Consider the discrete-time version of (34):

$$
\left\{\begin{array}{l}
\delta x\left(t_{m_{q+1}}\right)=A_{d}\left(x_{s}\left(t_{m_{0}}\right), u_{s}\left(t_{m_{0}}\right)\right) \delta x\left(t_{m_{q}}\right)+B_{d}\left(x_{s}\left(t_{m_{0}}\right), u_{s}\left(t_{m_{0}}\right)\right) \delta u\left(t_{m_{q}}\right), \\
y\left(t_{m_{q}}\right)=C \delta x\left(t_{m_{q}}\right)+y_{s}\left(t_{m_{0}}\right),
\end{array}\right.
$$

where $x\left(t_{m_{q}}\right), u\left(t_{m_{q}}\right)$ and $y\left(t_{m_{q}}\right)$ are the state vector, input vector and output vector at sampling instan$\mathrm{t} m T_{L}+q t_{l}, m=0,1, \ldots, N_{L}-1, q=0,1, \ldots, n_{l}-1 . \quad A_{d}\left(x_{s}\left(t_{m_{0}}\right), u_{s}\left(t_{m_{0}}\right)\right)=e^{A_{c}\left(x_{s}\left(t_{m_{0}}\right), u_{s}\left(t_{m_{0}}\right)\right) t_{l}}$, $B_{d}\left(x_{s}\left(t_{m_{0}}\right), u_{s}\left(t_{m_{0}}\right)\right)=\left(\int_{0}^{t_{l}} e^{A_{c}\left(x_{s}\left(t_{m_{0}}\right), u_{s}\left(t_{m_{0}}\right)\right) \tau} \mathrm{d} \tau\right) B_{c}\left(x_{s}\left(t_{m_{0}}\right), u_{s}\left(t_{m_{0}}\right)\right)$ are the system state matrix and input matrix, respectively.

The objective of the proposed MPC controller is to maintain the indoor air temperature, moisture content and $\mathrm{CO}_{2}$ concentration at the required levels with low energy cost. To achieve this aim, the cost function to be minimised can be chosen as

$$
\min _{\delta u} J\left(t_{m_{q}}\right)=\underbrace{\sum_{j=1}^{n_{p}}\left\|y\left(t_{m_{q+j}} \mid t_{m_{q}}\right)-r\left(t_{m_{q+j}}\right)\right\|^{2}}_{(a)}+R_{\delta u} \underbrace{\sum_{j=0}^{n_{c}-1}\left\|\delta u\left(t_{m_{q+j}}\right)\right\|^{2}}_{(b)},
$$

subject to:

$$
\begin{aligned}
& \left\{\begin{array}{l}
\delta x\left(t_{m_{l_{1}}} \mid t_{m_{q+1}}\right)=A_{d}\left(x_{s}\left(t_{m_{0}}\right), u_{s}\left(t_{m_{0}}\right)\right) \delta x\left(t_{m_{l_{1}-1}} \mid t_{m_{q}}\right)+B_{d}\left(x_{s}\left(t_{m_{0}}\right), u_{s}\left(t_{m_{0}}\right)\right) \delta u\left(t_{m_{l_{1}-1}} \mid t_{m_{q}}\right), \\
y\left(t_{m_{l_{1}-1}} \mid t_{m_{q}}\right)=C \delta x\left(t_{m_{l_{1}-1}} \mid t_{m_{q}}\right)+y_{s}\left(t_{m_{0}}\right),
\end{array}\right. \\
& \delta x\left(t_{m_{l_{1}}} \mid t_{m_{q}}\right)+x_{s}\left(t_{m_{0}}\right) \in \mathbb{X}, \delta u\left(t_{m_{l_{2}}}\right)+u_{s}\left(t_{m_{0}}\right) \in \mathbb{U}, \\
& l_{1}=q+1, \ldots, q+n_{p}, l_{2}=q, \ldots, q+n_{c}-1 \text {, } \\
& q=0,1, \ldots, n_{l}-1, m=0,1, \ldots, N_{L}-1 \text {. }
\end{aligned}
$$

where (a) penalizes the indoor air temperature, moisture content and $\mathrm{CO}_{2}$ concentration tracking error and (b) penalizes the balancing signal tracking error in quadratic forms. The current time index $t_{m_{q}}$ denotes the current time $m T_{L}+q t_{l} ; \mid t_{m_{q}}$ means that the predicted value is based on the information up to $t=m T_{L}+q t_{l}$; $n_{p}=T_{L} / t_{l}$ is the prediction horizon; $n_{c}=T_{L} / t_{l}$ is the control horizon; $r\left(t_{m_{q+j}}\right)$ is the reference vector at step $t_{m_{q+j}} ; y\left(t_{m_{q+j}} \mid t_{m_{q}}\right)$ is the predicted output vector at step $t_{m_{q+j}} ; \delta u\left(t_{m_{q+j}}\right)$ is the predicted control vector at step $t_{m_{q+j}} ; R_{\delta u}$ is used as a tuning parameter for the desired closed-loop performance.

Remark 5: The system matrices of the system (34) are updated to $A_{d}\left(x_{s}\left(t_{(m+1)_{0}}\right), u_{s}\left(t_{(m+1)_{0}}\right)\right)$ and $B_{d}\left(x_{s}\left(t_{(m+1)_{0}}\right), u_{s}\left(t_{(m+1)_{0}}\right)\right)$ when the system transiting from the sampling interval $\left[m T_{L}+\left(n_{l}-1\right) t_{l},(m+\right.$ 1) $\left.T_{L}\right)$ to $\left[(m+1) T_{L},(m+1) T_{L}+t_{l}\right)$. On the other hand, on sampling interval $\left[(m+1) T_{L},(m+1) T_{L}+t_{l}\right)$, the variables $\delta x\left(t_{m_{n_{l}-1}}\right)$ and $\delta u\left(t_{m_{n_{l}-1}}\right)$ as the initial points are fed to the system (37), and the references are updated in (36). The convergence for this periodic MPC for an optimisation problem over an infinite time horizon has been proven in $[53,54]$. 
The proposed MPC algorithm is as below:

Algorithm 2. MPC algorithm to the DX A/C tracking control problem.

Initialization: Given initial state value $x(0)$ and let $t_{m_{q}}=0(m=0, q=0)$.

1: Compute the optimal solution $\bar{U}\left(t_{m_{0}}\right)=\left[\bar{u}\left(t_{m_{0}}\right), \bar{u}\left(t_{m_{1}}\right), \ldots, \bar{u}\left(t_{m_{n_{l}-1}}\right)\right]^{T}$ of the problem formulated in (36) and (38).

2: Apply the MPC control $u_{m p c}\left(t_{m_{0}}\right)=\bar{u}\left(t_{m_{0}}\right)$ to the system in the sampling interval $\left[t_{m_{0}}, t_{m_{0}}+t_{l}\right)$; the rest of the solutions $\bar{u}\left(t_{m_{q}}\right), q=1, \ldots, n_{l}-1$ are discarded. $x\left(t_{m_{q+1}}\right)$ is calculated by $x\left(t_{m_{q+1}}\right)=$ $f\left(x\left(t_{m_{q}}\right), u_{m p c}\left(t_{m_{q}}\right)\right)$.

3: Set $t_{m_{q}}:=t_{m_{q+1}}$, and update system states, inputs and outputs with control $u_{m p c}\left(t_{m_{0}}\right)$ and state equation $x\left(t_{m_{q+1}}\right)=f\left(x\left(t_{m_{q}}\right), u_{m p c}\left(t_{m_{q}}\right)\right)$.

4: Until $t_{m_{q}}:=t_{m_{n_{l}-1}}$, and update system states, inputs and outputs; repeat the steps 1 and 2 , we have obtain that $u_{m p c}\left(t_{m_{n_{l}-1}}\right)=\bar{u}\left(t_{m_{n_{l}-1}}\right)$. Apply the MPC control $u_{m p c}\left(t_{m_{n_{l}-1}}\right)$ to the system in the sampling interval $\left[t_{m_{n_{l}-1}}, t_{(m+1)_{0}}\right)$.

5: Set $t_{m_{q}}:=t_{(m+1)_{0}}$, measure the state value $x\left(t_{m_{n_{l}-1}}\right)$ by the step $t_{m_{q}}=t_{m_{n_{l}-1}}$, and $u_{m p c}\left(t_{m_{n_{l}-1}}\right)$ to the system $x\left(t_{(m+1)_{0}}\right)=f\left(x\left(t_{m_{n_{l}-1}}\right), u_{m p c}\left(t_{m_{n_{l}-1}}\right)\right)$, and update reference $r\left(t_{m_{0}}\right):=r\left(t_{(m+1)_{0}}\right)$ in $(36)$.

6: Compute the optimal solution $\bar{U}\left(t_{(m+1)_{0}}\right)=\left[\bar{u}\left(t_{(m+1)_{0}}\right), \bar{u}\left(t_{(m+1)_{1}}\right), \ldots, \bar{u}\left(t_{\left.(m+1)_{n_{l}-1}\right)}\right)\right]^{T}$ of the problem formulated in (36) and (38). Then the MPC control $u_{m p c}\left(t_{(m+1)_{0}}\right)=\bar{u}\left(t_{(m+1)_{0}}\right)$ (the remaining $\bar{u}\left(t_{(m+1)_{q}}\right), q=1, \ldots, n_{l}-1$ are discarded) is applied to the system in the sampling interval $\left[t_{(m+1)_{0}}, t_{(m+1)_{0}}+\right.$ $\left.t_{l}\right)$ to obtain the closed-loop MPC solution $x\left(t_{(m+1)_{1}}\right)=f\left(x\left(t_{(m+1)_{0}}\right), u_{m p c}\left(t_{(m+1)_{0}}\right)\right)$ over the period $\left[t_{(m+1)_{0}}+t_{l}, t_{(m+1)_{0}}+2 t_{l}\right)$.

7: Set $t_{m_{q}}:=t_{(m+1)}$ and go to step 1 .

Generally, the above MPC algorithm never stops, and it updates the controller at each time interval $\left[t_{m_{q}}, t_{m_{q+1}}\right)$ to include feedback information.

\section{Results}

Here, a case study is presented to demonstrate the performance of the closed-loop system with the proposed hierarchical control for the DX A/C system. The proposed hierarchical control strategy is compared with a baseline strategy through simulations over a 24-hour period.

\subsection{System setup}

In the case study, an office room is taken as the conditioned space. The volume of the DX conditioned space is $77 \mathrm{~m}^{3}$. The parameters of the DX A/C system are listed in Table 1. For the proposed hierarchical control strategy, the values of the system dynamic variable constraints are listed in Table 2, and we constrain the value of the PMV in the range of $[-0.5,0.5]$ to ensure that the DX A/C system is able to control indoor thermal comfort and IAQ at acceptable levels. The coefficients of the energy consumption models (23) of the DX A/C system are taken from [52], which are summarized in Table 3.

Table 1: Parameters of system model

\begin{tabular}{lllr}
\hline Notations & Values & Notations & Values \\
\hline$\rho$ & $1.2 \mathrm{~kg} / \mathrm{m}^{3}$ & $h_{f g}$ & $2450 \mathrm{~kJ} / \mathrm{kg}$ \\
$V$ & $77 \mathrm{~m}^{3}$ & $\varepsilon_{\text {win }}$ & 0.45 \\
$V_{h 1}$ & $0.04 \mathrm{~m}^{3}$ & $V_{h 2}$ & $0.16 \mathrm{~m}^{3}$ \\
$k_{s p l}$ & $0.0251 \mathrm{~kJ} / \mathrm{m}^{3}$ & $C_{z}$ & $1.005 \mathrm{~kJ} \mathrm{~kg}^{-1} \mathrm{C}^{-1}$ \\
$A_{0}$ & $22.07 \mathrm{~m}^{2}$ & & \\
\hline
\end{tabular}

In this paper, data of the outside temperature and relative humidity in a single summer are given, as shown in Fig. 5(a). The data is obtained from a meteorological station located in Cape Town, South Africa. The predicted solar radiative heat flux density profile of Cape Town is shown in Fig. 5(b). The certainty 
Table 2: Constraints of system variables

\begin{tabular}{lllr}
\hline Notations & Values & Notations & Values \\
\hline $\bar{T}_{s}$ & $22^{\circ} \mathrm{C}$ & $\underline{T}_{s}$ & $8{ }^{\circ} \mathrm{C}$ \\
$\bar{T}_{z}$ & $26{ }^{\circ} \mathrm{C}$ & $\underline{T}_{z}$ & $22{ }^{\circ} \mathrm{C}$ \\
$\bar{T}_{d}$ & $2{ }^{\circ} \mathrm{C}$ & $\underline{T}_{d}$ & $10{ }^{\circ} \mathrm{C}$ \\
$\bar{T}_{w}$ & $22{ }^{\circ} \mathrm{C}$ & $\underline{T}_{w}$ & $10{ }^{\circ} \mathrm{C}$ \\
$\bar{W}_{z}$ & $12.3 / 1000 \mathrm{~kg} / \mathrm{kg}$ & $\underline{W}_{z}$ & $9.85 / 1000 \mathrm{~kg} / \mathrm{kg}$ \\
$\bar{C}_{c}$ & $800 \times 10^{-6} \mathrm{ppm}$ & $\underline{C}_{c}$ & $650 \times 10^{-6} \mathrm{ppm}$ \\
$\bar{W}_{s}$ & $9.85 / 1000 \mathrm{~kg} / \mathrm{kg}$ & $\underline{W}_{s}$ & $7.85 / 1000 \mathrm{~kg} / \mathrm{kg}$ \\
$\bar{h}_{s}$ & $46.3 \mathrm{~kJ} / \mathrm{kg}$ & $\underline{h}_{s}$ & $27.3 \mathrm{~kJ} / \mathrm{kg}$ \\
$\bar{v}_{f}$ & $0.8 \mathrm{~m}^{3} / \mathrm{s}$ & $\underline{v}_{f}$ & $0 \mathrm{~m} / \mathrm{s}$ \\
$\bar{m}_{r}$ & $0.11 \mathrm{~kg} / \mathrm{s}$ & $\underline{\underline{m}}_{r}$ & $0 \mathrm{~kg} / \mathrm{s}$ \\
\hline
\end{tabular}

Table 3: Coefficients of energy consumption models

\begin{tabular}{lllr}
\hline Notations & Values & Notations & Values \\
\hline$a_{0}$ & 900.5 & $a_{1}$ & -8.1 \\
$a_{2}$ & 6.18 & $a_{3}$ & -0.15 \\
$a_{4}$ & -4.61 & $a_{5}$ & 0.02 \\
$a_{6}$ & -0.2 & $a_{7}$ & 0.01 \\
$a_{8}$ & 0.12 & $a_{9}$ & 0.09 \\
$b_{0}$ & -6942 & $b_{1}$ & 82 \\
$b_{2}$ & -0.7 & $b_{3}$ & 2.4 \\
$b_{4}$ & -2.5 & $b_{5}$ & 2.68 \\
$b_{6}$ & 0.03 & $b_{7}$ & -0.02 \\
$b_{8}$ & 0.04 & $b_{9}$ & 0.0001 \\
$c_{0}$ & 138.1 & $c_{1}$ & 0.52 \\
$c_{2}$ & -2.3 & & \\
\hline
\end{tabular}

internal sensible and latent heat loads, the external sensible heat load and pollutant load in the conditioned space are predicted in Fig. 6. The values in Figs. 5-6 at every hour are commensurately quantised. It is assumed that the PI controller can absorb the $\mathrm{CO}_{2}$ concentration in the air supply, where $C_{s}=360 \mathrm{ppm}$ is used in this paper.

The TOU schedule for summer hours is summarized in (29); for simplicity, only the TOU energy charge is used in the cost function. The unit of Relative Humidity $(\mathrm{RH})$ is percent $(\%) . \frac{11.35}{1000} \mathrm{~kg} / \mathrm{kg}$ of moisture content is equivalent to $60 \% \mathrm{RH}$ in the conditioned space. In addition, the original nonlinear system (27) is used as the system to be controlled in the simulation.

\subsection{Two scheduling strategies}

Here, we consider two strategies to schedule the operation of the DX A/C system in the conditioned space. One is energy optimised open loop controller and the closed-loop regulation of the MIMO MPC approach, which serves as a baseline strategy [42], and the other is the proposed energy and comfort optimised open loop controller and the closed-loop tracking of the MIMO MPC strategy. To simplify the comparison, the predicted load profiles are the same in both control strategies.

1) Baseline: The baseline can be described as follows: We first select a setpoint for indoor air temperature and relative humidity based on a comfort zone within the psychrometric chart and a setpoint for $\mathrm{CO}_{2}$ concentration based on the required level of occupants. The ASHRAE comfort zone is shown in [55]. Its details are omitted here because of space limitations. Under the given setpoint, we can obtain a unique 


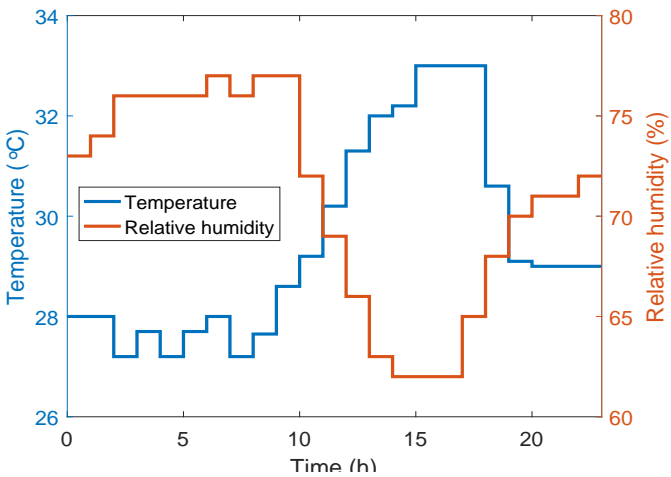

(a)

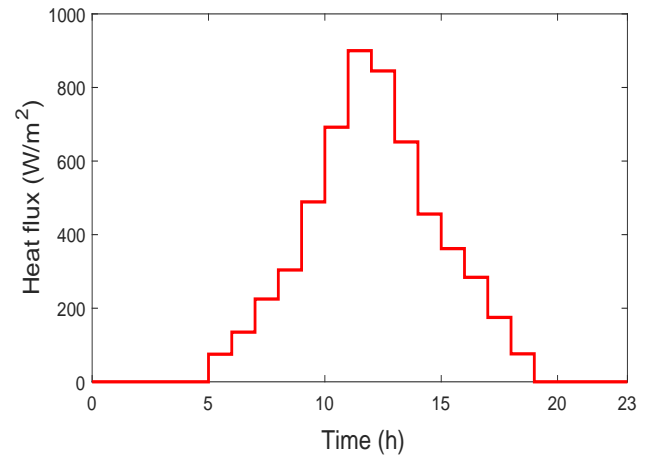

(b)

Figure 5: (a) Profiles of outside temperature and relative humidity over a 24-hour period. (b) Profiles of radiative heat flux over a 24 -hour period.

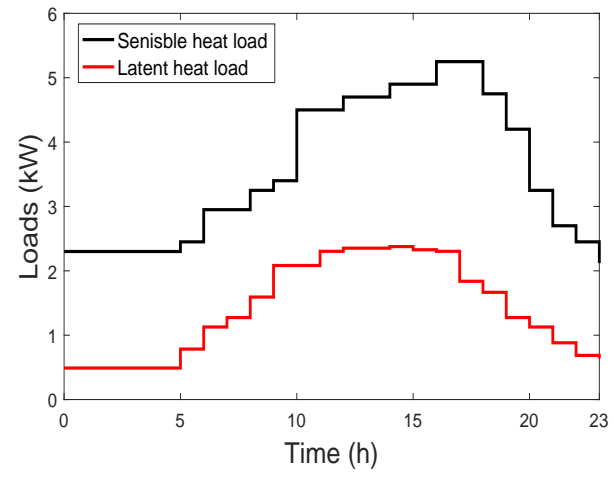

(a)

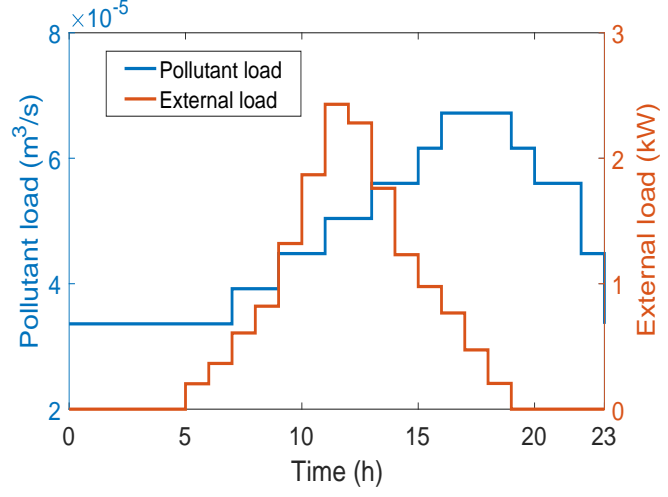

(b)

Figure 6: (a) Certainty internal sensible and latent heat loads. (b) pollutant load and external sensible heat load.

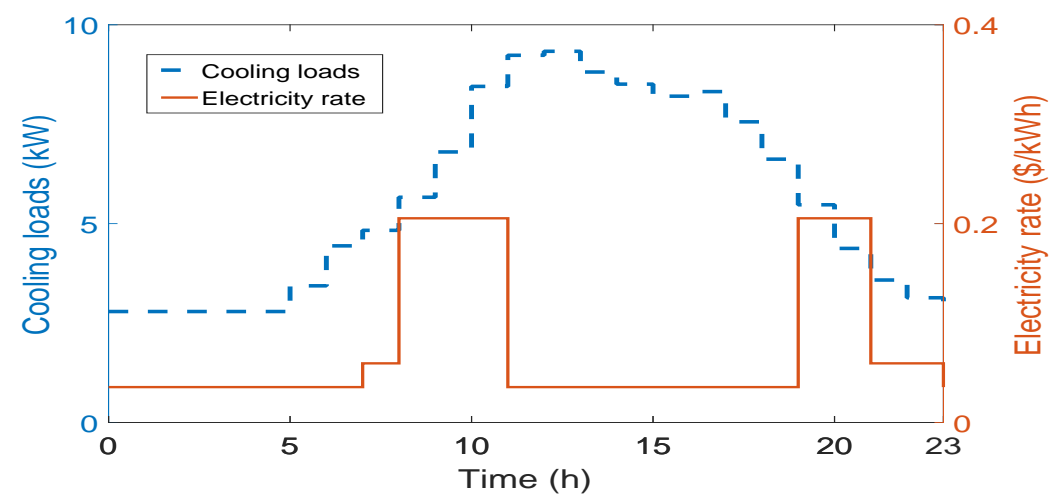

Figure 7: Cooling loads and electricity rates over a 24-hour period.

steady state of the DX A/C system by solving the equations (1), (3), (5)-(6) and (9)-(10) at every hour over a 24-hour period. The nonlinear model is then linearised around its steady state. An MPC is designed for the linearised model. The proposed MPC with sampling period $2 \mathrm{~min}$ is applied to achieve better performance on thermal comfort and IAQ with superior energy efficiency simultaneously. 
2) Proposed method: For the proposed control strategy, the details are also given as below: We first consider the open loop controller to solve the optimization problem (30) to obtain steady states at every hour. The open loop controller and closed-loop MPC are employed to track the references of temperature, humidity and $\mathrm{CO}_{2}$ concentration. In the proposed control method, the volume of the outside air entering indoor is optimized. The optimal volume of the outside air is used in the DX A/C system for closed-loop MPC controller. The sampling period is set to $T_{L}=1 \mathrm{~h}$; the sampling interval is set to $N_{L}=24$ hour; the sampling period for MPC design is $t_{l}=2 \mathrm{~min}$, the prediction horizon and control horizon are taken as $n_{p}=n_{c}=30$ in the lower layer. At each time step, the open loop controller is employed to solve the optimization problem (30) and the steady states obtained are sent to the lower layer. In Section 4.3, we will compare the energy consumption and energy cost for the baseline and the proposed strategies next.

\subsection{Comparison of two strategies}

The performance of both strategies is compared with historical weather data of a specific day in Cape Town. The total simulation time is $K=24 \mathrm{~h}$. The predicted indoor cooling loads profile is depicted in Fig. 7 overlaid with an electricity rate for summer hours. We duplicate the indoor cooling loads profile for the next day to simulate the MPC scheme. The temperature profile of the air leaving the DX evaporator and $\mathrm{p} \%$ of the outside air entering into the system over a 24-hour period are shown in Fig. 8(a) and 8(b). The data is used in the DX A/C system for closed-loop tracking control.

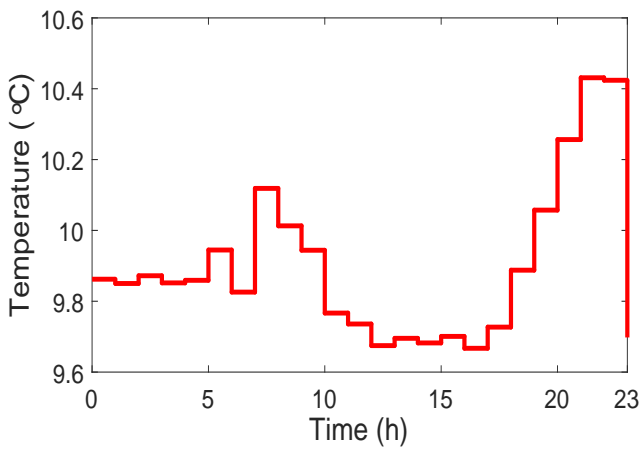

(a)

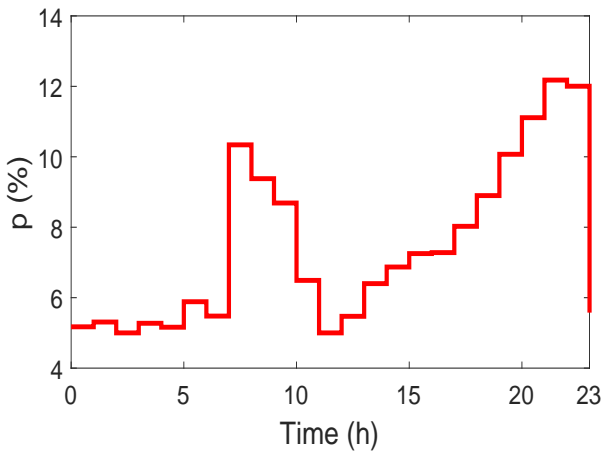

(b)

Figure 8: (a) Supply air temperature over a 24-hour period. (b) p\% of fresh air entering into the system over a 24-hour period.

The controls computed from two strategies are applied to the DX A/C system. The tracking reference points of indoor air temperature in the conditioned space for the proposed strategy and the setpoint regulation of indoor air temperature for the baseline strategy are depicted in Fig. 9(a). The tracking reference points of indoor air relative humidity in the conditioned space for the proposed strategy and the setpoint regulation of indoor air relative humidity for the baseline strategy are depicted in Fig. 9(b). The tracking reference points of indoor $\mathrm{CO}_{2}$ concentration in the conditioned space for the proposed strategy and the setpoint regulation of indoor $\mathrm{CO}_{2}$ concentration for the baseline strategy are depicted in Fig. 9(c). We observe that the indoor temperature, humidity and $\mathrm{CO}_{2}$ concentration for the proposed strategy can track their reference points well. We also observe that for the proposed strategy the reference points are tallish during peak hours for temperature and humidity tracking. This is because the proposed controller can automatically adjust the reference points upward during peak hours such that the energy cost and energy consumption are minimized while both the thermal comfort and IAQ still maintain in the acceptable ranges. We further observe that with the baseline strategy under the varying loads, the MPC controller always maintains the indoor temperature, humidity and $\mathrm{CO}_{2}$ concentration at their setpoint by regulating the control inputs. From the local zooming out of Fig. 9, the reference points of indoor air temperature, humidity and $\mathrm{CO}_{2}$ concentration are reached after a transient process of $18 \mathrm{~min}$. After reaching their reference points, 
the proposed controller maintains the reference points with small variation ranges. Fig. 10 shows the air volumetric flow rate and mass flow rate of refrigerant over a 24-hour period. The two input variables vary to drive the indoor air temperature, humidity and $\mathrm{CO}_{2}$ concentration to track their trajectory references according to the changing environment during the day. In Fig. 11, it can be observed that the values of the PMV index for the two control methods lie within the expected range $[-0.5,0.5]$.

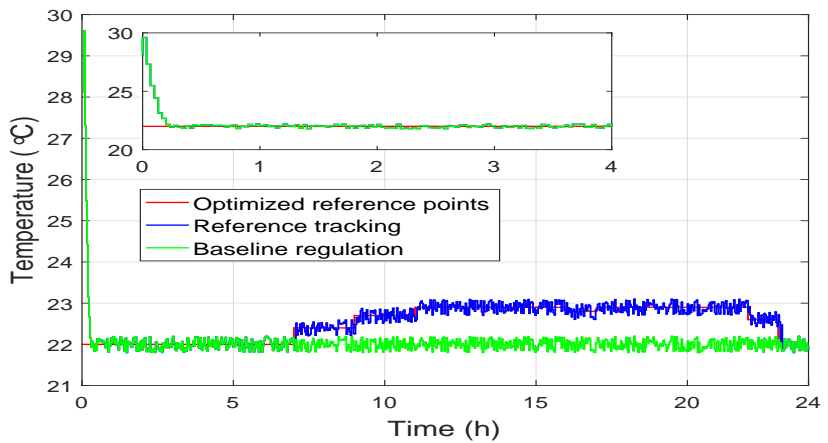

(a)

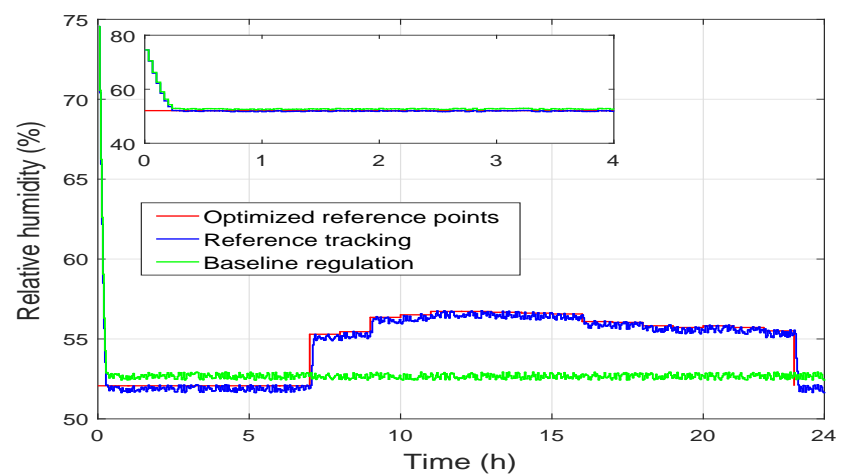

(b)

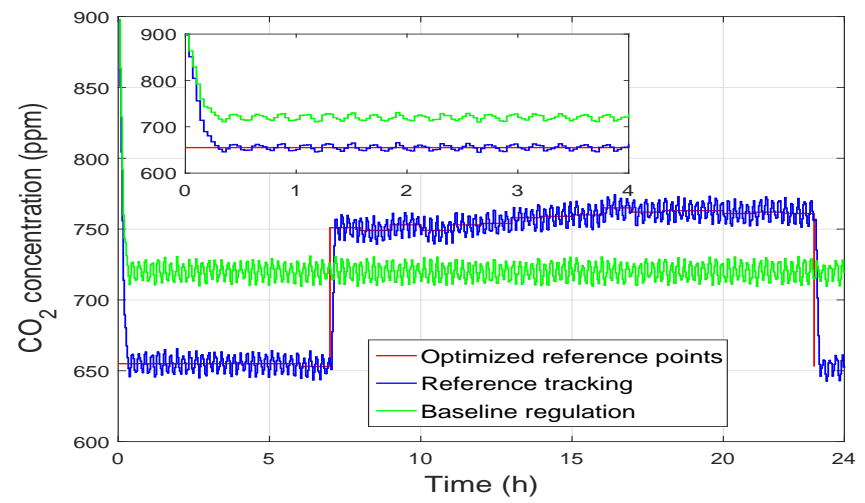

(c)

Figure 9: (a) Temperature tracking. (b) Relative humidity tracking. (c) $\mathrm{CO}_{2}$ concentration tracking. 


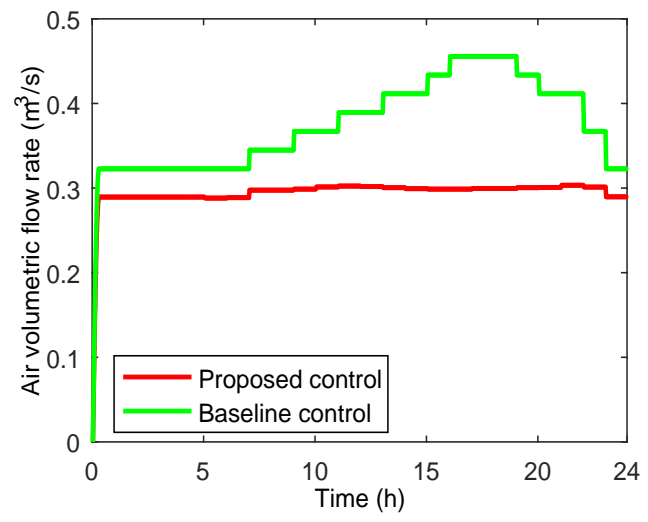

(a)

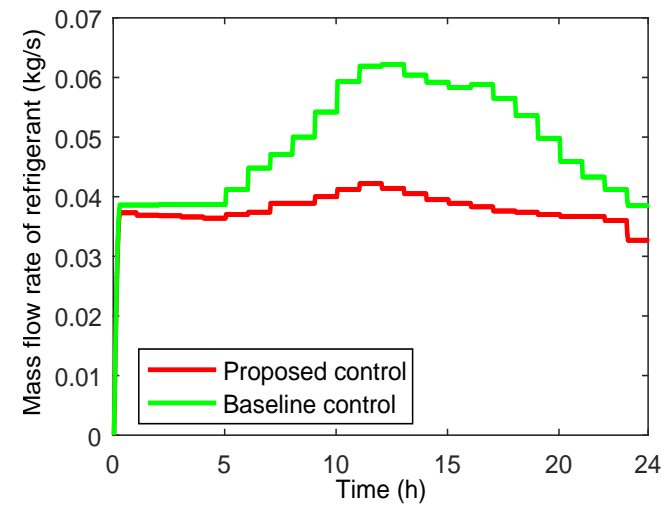

(b)

Figure 10: (a) Air volumetric flow rate over a 24-hour period. (b) Mass flow rate of refrigerant over a 24-hour period.

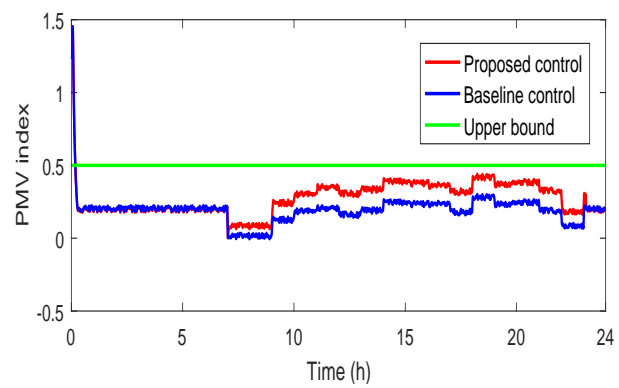

Figure 11: Profile of the value of the PMV index over a 24-hour period.

Figs. 12(a) and 12(b) illustrate the energy consumption and cost of the DX A/C system operation for the proposed strategy and the baseline strategy. We observe from Fig. 12(a) and 12(b) that both strategies consume almost the same energy cost from 0:00 to 7:00. The indoor temperature, humidity and $\mathrm{CO}_{2}$ concentration reference points stay at the lower bound of the PMV index during off-peak hours without more cost. After 8:00, the energy costs of the baseline and proposed strategies start to increase since the increased cooling loads are required to be removed and the electric power price is increased. Compared to the baseline strategy, Fig. 12(a) shows that the proposed method consumes less energy. Comparing the two strategies, we observe that under the proposed method, more energy costs are reduced during peak hours. The reason is that the proposed method automatically adjusts upward the reference points such that the energy consumption and the energy costs are minimized during peak hours while maintaining both thermal comfort and IAQ at the required levels. From the simulation, it is verified that the major energy consumption and costs have been reduced effectively during peak hours. We summarize the total energy consumption, energy cost and comfort levels in Table 4. According to it, the proposed hierarchical control strategy performs better than the baseline by around $31.38 \%$ in terms of total energy consumption, and by around $33.85 \%$ in terms of total energy cost. It can be seen from Table 4 that the proposed control strategy presents a lower energy consumption and costs compared to the baseline control strategy. The table also shows that the total values of the PMV index for the proposed control strategy is higher than that of the baseline control strategy. It is expected that the proposed control strategy reduces energy consumption and cost at the expenses of the comfort level, which is still reasonably and optimally regulated to acceptable levels. Therefore, the utilities can choose the two control strategies to implement building DX A/C systems based on their different aims.

Though it is desirable to calculate the cost savings brought by the proposed control strategy over the 


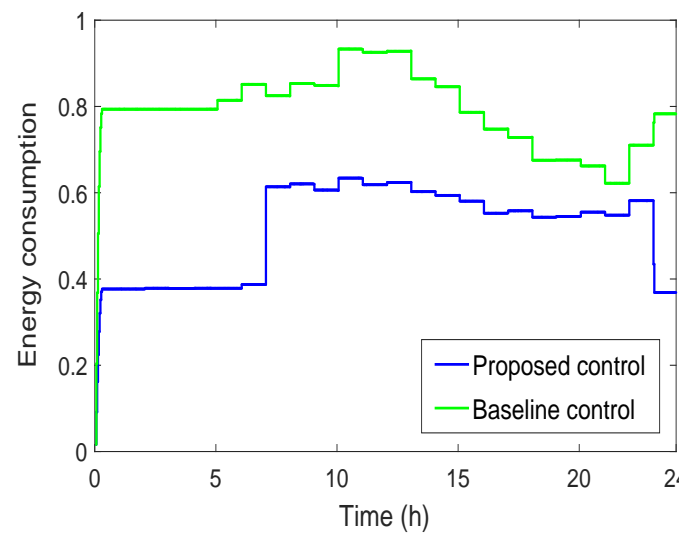

(a)

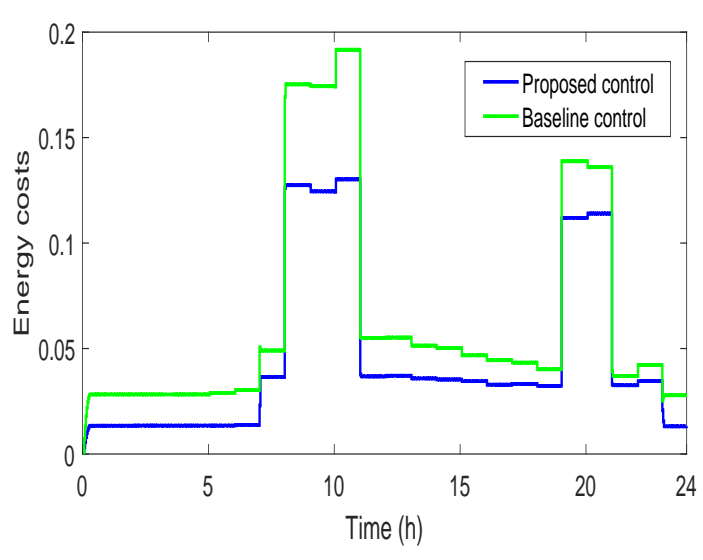

(b)

Figure 12: (a) Energy consumption by two strategies over a 24-hour period. (b) Energy cost by two strategies over a 24 -hour period.

Table 4: Comparison of baseline and proposed strategies

\begin{tabular}{lllr}
\hline Control strategy & Energy consumption $(\mathrm{kWh})$ & Energy cost $(\$)$ & $\sum|\mathrm{PMV}|$ \\
\hline Baseline control & 20.52 & 1.734 & 103.33 \\
Proposed control & 14.08 & 1.147 & 162.32 \\
Saving (\%) & 31.38 & 33.85 & \\
\hline
\end{tabular}

baseline strategy, it is an impossible task for real buildings to simply compare the cost values of two control strategies in one day because load factors and ambient temperature and humidity cannot be the same in every day. To demonstrate the effectiveness of the proposed automatic hierarchical control strategy in different conditions, the proposed testing days happened to be much warmer than the baseline days in this test. The weather conditions of the testing days are shown in Table 5. The energy consumption in the testing days is shown in Fig. 13. From this comparison, all proposed control testing days have much lower power consumption, showing successful energy efficiency improvement by the proposed control strategy.

Table 5: Weather conditions for the testing days

\begin{tabular}{lllllr}
\hline Date & Control & Average $T_{0}$ & Average $H_{0}$ & $T_{0}^{\max }$ & $H_{0}^{\max }$ \\
\hline $12 / 30$ & Baseline & 28.6 & $72.4 \%$ & 33.9 & $80 \%$ \\
$12 / 31$ & Proposed & 29.2 & $71.6 \%$ & 34.2 & $81 \%$ \\
$01 / 01$ & Proposed & 28.8 & $72.1 \%$ & 32.2 & $79 \%$ \\
$01 / 02$ & Proposed & 28.9 & $72.4 \%$ & 33.2 & $81 \%$ \\
$01 / 03$ & Proposed & 28.1 & $73.2 \%$ & 32.0 & $82 \%$ \\
$01 / 04$ & Baseline & 28.0 & $72.3 \%$ & 32.4 & $79 \%$ \\
$01 / 05$ & Baseline & 27.6 & $73.4 \%$ & 32.0 & $80 \%$ \\
\hline
\end{tabular}

\subsection{Parameter sensitivities analysis}

The simulation results presented here are obtained under the assumption that the parameters are accurate and the DX A/C system models can perfectly represent the real system. However, in reality, there usually exist uncertainties in parameters and models. In this section, a simple uncertainty analysis is carried out to demonstrate how the uncertainty parameter would affect the potential performance of the proposed 


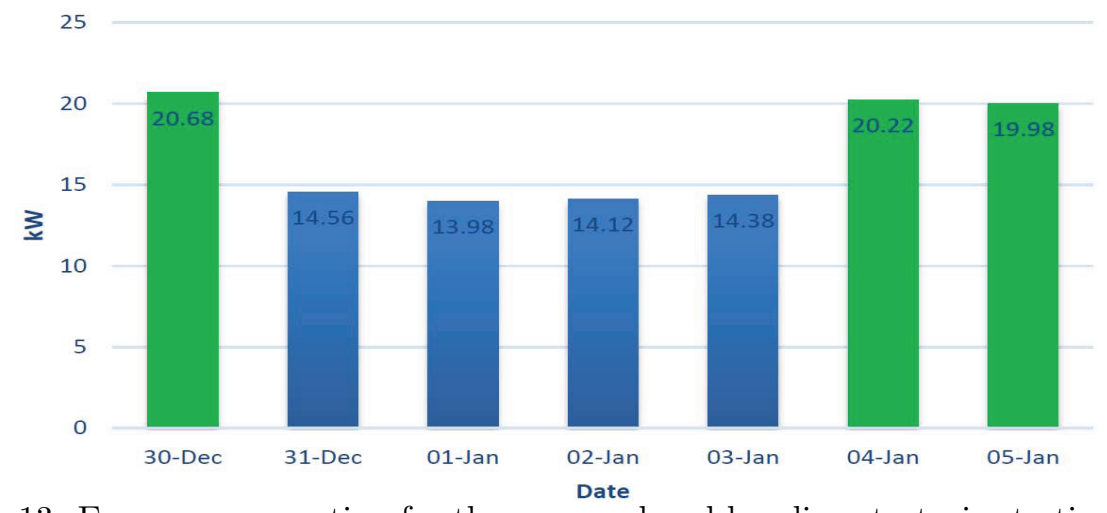

Figure 13: Energy consumption for the proposed and baseline strategies testing days.

autonomous hierarchical control strategies. Here, we consider the uncertainties of some major parameters of the DX A/C system, namely, the heat transfer area of the DX evaporator in the dry-cooling region $A_{1}$ and the heat transfer area of the DX evaporator in the wet-cooling region $A_{2}$. The total area $A_{0}=A_{1}+A_{2}$ is known. Hence, it is only necessary to consider the effect of the uncertainty parameter $A_{1}$ on the performance of the proposed control technique. The open loop optimal controller and the closed-loop tracking of the MPC with different values of the uncertainty parameter $A_{1}$ are verified through simulation. For the case study considered here, the simulations for indoor air temperature optimised by open loop optimal controller and the closed-loop MPC temperature tracking under different parameter values are depicted in Figs. 14-15, and the results for the open loop optimal controller under all different ranges of the uncertainty parameter are listed in Table 6 . The standard deviations for the steady state of indoor air temperatures are less than $0.2{ }^{\circ} \mathrm{C}$. The standard deviations for the objective function values of the open loop controller are less than $6 \%$. The results show that the fluctuation of the control performances caused by parameter uncertainty is relatively small. Thus, the proposed autonomous hierarchical control strategy is not very sensitive to the modeling parameter $A_{1}$ specified here.

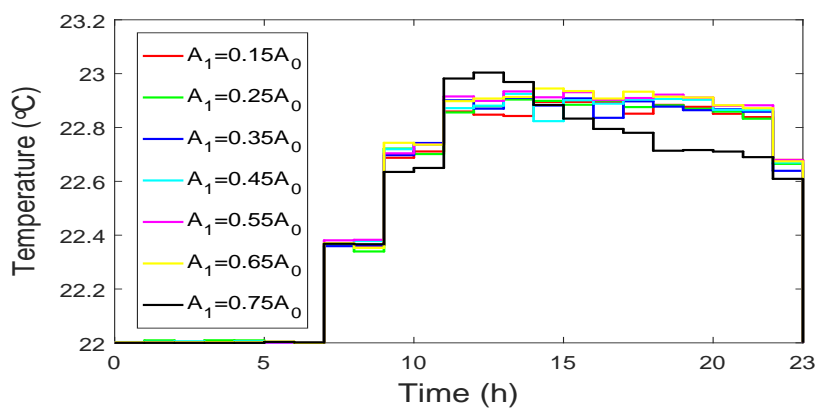

Figure 14: Steady state of indoor air temperature optimised by the open loop controller under different values of the dry-cooling regions.

\section{Conclusions}

This work formulates an autonomous hierarchical control problem to minimize energy consumption and cost while maintaining both thermal comfort and indoor air quality at the required levels for supervisory control of a direct expansion air conditioning system. It proposes an efficient control algorithm to solve the autonomous hierarchical control problem based on nonlinear programming and closed-loop model predictive control. The optimal reference points of indoor air temperature, humidity and $\mathrm{CO}_{2}$ concentration for the 


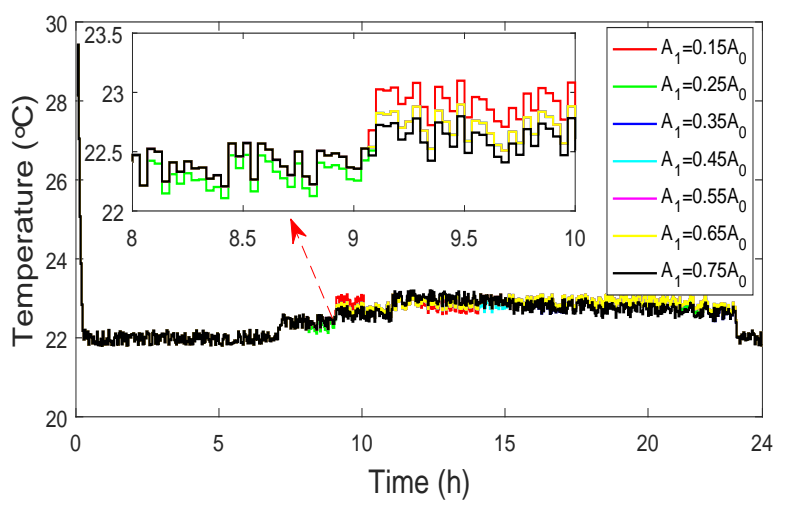

Figure 15: Closed-loop MPC temperature tracking under different values of the dry-cooling regions.

Table 6: Open loop optimization results under different values of the dry-cooling regions.

\begin{tabular}{lllr}
\hline $\begin{array}{l}\text { Objective function value } \\
\text { of open loop optimization }\end{array}$ & $\begin{array}{l}\text { Area of } \\
\text { dry region }\end{array}$ & $\begin{array}{l}\text { Portion of } A_{1} \\
\mathrm{~m}^{2}\end{array}$ & $\begin{array}{r}\text { Derivation } \\
\%\end{array}$ \\
\hline 43.04 & $\left(0,0.05 A_{0}\right]$ & $0.05 A_{0}$ & $2.14 \%$ \\
44.23 & $\left(0.05 A_{0}, 0.10 A_{0}\right]$ & $0.10 A_{0}$ & $0.57 \%$ \\
$\mathbf{4 3 . 9 8}$ & $\left(\mathbf{0 . 1} \boldsymbol{A}_{\mathbf{0}}, \mathbf{0 . 1 5 \boldsymbol { A } _ { \mathbf { 0 } } ]}\right.$ & $\mathbf{0 . 1 5 \boldsymbol { A } _ { \mathbf { 0 } }}$ & \\
43.00 & $\left(0.15 A_{0}, 0.20 A_{0}\right]$ & $0.20 A_{0}$ & $2.23 \%$ \\
43.20 & $\left(0.2 A_{0}, 0.25 A_{0}\right]$ & $0.25 A_{0}$ & $1.77 \%$ \\
43.48 & $\left(0.25 A_{0}, 0.30 A_{0}\right]$ & $0.30 A_{0}$ & $1.14 \%$ \\
42.87 & $\left(0.3 A_{0}, 0.35 A_{0}\right]$ & $0.35 A_{0}$ & $2.52 \%$ \\
41.57 & $\left(0.35 A_{0}, 0.40 A_{0}\right]$ & $0.40 A_{0}$ & $5.48 \%$ \\
42.54 & $\left(0.4 A_{0}, 0.45 A_{0}\right]$ & $0.45 A_{0}$ & $3.27 \%$ \\
42.47 & $\left(0.45 A_{0}, 0.50 A_{0}\right]$ & $0.50 A_{0}$ & $3.43 \%$ \\
42.21 & $\left(0.50 A_{0}, 0.55 A_{0}\right]$ & $0.55 A_{0}$ & $4.02 \%$ \\
42.26 & $\left(0.55 A_{0}, 0.60 A_{0}\right]$ & $0.65 A_{0}$ & $3.91 \%$ \\
44.00 & $\left(0.60 A_{0}, 0.70 A_{0}\right]$ & $0.70 A_{0}$ & $0.04 \%$ \\
42.22 & $\left(0.70 A_{0}, 0.75 A_{0}\right]$ & $0.75 A_{0}$ & $4.00 \%$ \\
41.91 & $\left(0.75 A_{0}, 0.80 A_{0}\right]$ & $0.80 A_{0}$ & $4.71 \%$ \\
41.60 & $\left(0.80 A_{0}, 0.85 A_{0}\right]$ & $0.85 A_{0}$ & $5.41 \%$ \\
41.52 & $\left(0.85 A_{0}, 0.90 A_{0}\right]$ & $0.90 A_{0}$ & $5.59 \%$ \\
41.70 & $\left(0.90 A_{0}, 0.95 A_{0}\right]$ & $0.95 A_{0}$ & $5.18 \%$ \\
\hline
\end{tabular}

direct expansion air conditioning system are obtained, and the closed-loop model predictive controller steers the direct expansion air conditioning system to reach the reference points, whereas the energy consumption and energy costs are reduced. Results show that the proposed control method could achieve a reduction of the operation energy consumption by $33.9 \%$ and cost by $33.85 \%$ with the predicted mean vote value in $[-0.5,0.5]$, respectively. The performances of the proposed control are obtained under the assumption that the models and parameters can perfectly represent the real system. However, in reality, there usually exist uncertainties. The uncertainty analysis has been made in this paper. The results show that the proposed control method is effective because the standard deviations of energy savings are less than $5 \%$ in comparison with around $35 \%$ energy saving for normal values. The proposed control method is significant to be applied in theoretical and practical applications. 


\section{Acknowledgement}

The first author would like to express my sincere appreciation to Dr. Xiangguo Xu for his valuable suggestions and academic discussion.

\section{References}

[1] D. Setlhaolo, X. Xia, J. Zhang, Optimal scheduling of household appliances for demand response, Electric Power Systems Research, vol. 116, pp. 24-28, 2014.

[2] D. Setlhaolo, X. Xia, Optimal scheduling of household appliances with a battery storage system and coordination, Energy and Buildings, vol. 94, pp. 61-70, May 2015.

[3] D. Setlhaolo, X. Xia, Combined residential demand side management strategies with coordination and economic analysis, International Journal of Electrical Power and Energy Systems, vol. 79, pp. 150-160, 2016.

[4] H. Tazvinga, X. Xia, J. Zhang, Minimum cost solution of photovoltaic-diesel-battery hybrid power systems for remote consumers, Solar Energy, vol. 96, pp. 292-299, 2013.

[5] H. Tazvinga, B. Zhu, X. Xia, Energy dispatch strategy for a photovoltaic-wind-diesel-battery hybrid power system, Solar Energy, vol. 108, pp. 412-420, 2014.

[6] H. Tazvinga, B. Zhu, X. Xia, Optimal power flow management for distributed energy resources with batteries, Energy Conversion and Management, vol. 102, pp. 104-110, 2015.

[7] B. Zhu, H. Tazvinga, X. Xia, Switched model predictive control for energy dispatching of a photovoltaic-diesel-battery hybrid power system, IEEE Trans. Control Syst. Tech., vol. 23, pp. 1229-1236, 2015.

[8] Z. Wu, X. Xia, Optimal switching renewable energy system for demand side management, Solar Energy, vol. 114, pp. $278-288,2015$.

[9] B. Wang, X. Xia, J. Zhang, A multi-objective optimization model for the life-cycle cost analysis and retrofitting planning of buildings, Energy and Buildings, vol. 77, pp. 227-235, 2014.

[10] B. Wang, X. Xia, Optimal maintenance planning for building energy efficiency retrofitting from optimization and control system perspectives, Energy and Buildings, vol. 96, pp. 299-308, 2015.

[11] Z. Wu, X. Xia, B. Wang, Improving building energy efficiency by multiobjective neighborhood field optimization, Energy and Buildings, vol. 87, pp. 45-56, 2015.

[12] B. Wang, Z. Wu, X. Xia, A multistate-based control system approach toward optimal maintenance planning, IEEE Trans. Control Syst. Technol., vol. 25, no. 1, pp. 374-381, 2017.

[13] Z. Wu, B. Wang, X. Xia, Large-scale building energy efficiency retrofit: Concept, model and control, Energy, vol. 109, pp. 456-465, 2016.

[14] Y. Fan, X. Xia, A multi-objective optimization model for energy-efficiency building envelope retrofitting plan with rooftop PV system installation and maintenance, Applied Energy, vol. 189, pp. 327-335, 2017.

[15] E.M. Wanjiru, L. Zhang, X. Xia, Model predictive control strategy of energy-water management in urban households, Applied Energy, vol. 179, pp. 821-831, 2016.

[16] E.M. Wanjiru, S.M. Sichilalu, X. Xia, Model predictive control of heat pump water heater-instantaneous shower powered with integrated renewable-grid energy systems, Applied Energy, vol. 204, pp. 1333-1346, 2017.

[17] P. Morosan, R. Bourdais, D. Dumur, J. Buisson, Building temperature regulation using a distributed model predictive control, Energy and Buildings, vol. 42, no. 9, pp. 1445-1452, 2010.

[18] J. Ma, S.J. Qin, T. Salsbury, P. Xu, Demand reduction in building energy systems based on economic model predictive control, Chemical Engineering Science, vol. 67, no. 1, pp. 92-100, 2012.

[19] Z. Váňa, J. Cigler, J. Široký, E. Žáčeková, L. Ferkl, Model-based energy efficient control applied to an office building, Journal of Process Control, vol. 24, no. 6, pp. 790-797, 2014.

[20] M. Razmara, M. Maasoumy, M. Shahbakhti, R.D. Robinett, Optimal exergy control of building HVAC system, Applied Energy, vol. 156, pp. 555-565, 2015.

[21] S. Zhang, Y. Cheng, Z. Fang, C. Huan, Z. Lin, Optimization of room air temperature in stratum-ventilated rooms for both thermal comfort and energy saving, Applied Energy, vol. 204, pp. 420-431, 2017.

[22] J. Cigler, S. Prívara, Z. Váňa, E. Žáčeková, L. Ferkl, Optimization of predicted mean vote index within model predictive control framework: Computationally tractable solution, Energy and Buildings, vol. 52, pp. 39-49, 2012.

[23] M. Castilla, J. D. Álvarez, J. E. Normey-Rico, F. Rodríguez, Thermal comfort control using a non-linear MPC strategy: A real case of study in a bioclimatic building, Journal of Process Control, vol. 24, no. 6, pp. 703-713, 2014.

[24] M. Castilla, J. D. Álvarez, M. Berenguel, F. Rodríguez, J. L. Guzmán, M. Pérez, A comparison of thermal comfort predictive control strategies, Energy and Buildings, vol. 43, no. 10, pp. 2737-2746, 2011.

[25] J. Ma, S.J. Qin, T. Salsbury, Application of economic MPC to the energy and demand minimization of a commercial building, Journal of Process Control, vol. 24, no. 8, pp. 1282-1291, 2014.

[26] Y. Ma, J. Matuško, F. Borrelli, Stochastic model predictive control for building HVAC systems: Complexity and conservation, IEEE Trans. Control Syst. Technol., vol. 23, no. 1, pp. 101-116, 2015.

[27] T. Salsbury, P. Mhaskar, S.J. Qin, Predictive control methods to improve energy efficiency and reduce demand in buildings, Computers and Chemical Engineering, vol. 51, pp. 77-85, 2013.

[28] J. Toftum, P.O. Fanger, Air humidity requirements for human comfort, ASHRAE Transactions, vol. 105, pp. 641-647, 1999. 
[29] R. Freire, G. Oliveira, N. Mendes, Predictive controllers for thermal comfort optimization and energy savings, Energy and Buildings, vol. 40, no. 7, pp. 1353-1365, 2008.

[30] Q. Qi, S. Deng, Multivariable control of indoor air temperature and humidity in a direct expansion (DX) air conditioning (A/C) system, Building and Environment, vol. 44, no. 8, pp. 1659-1667, 2009.

[31] X. Xu, L. Xia, M. Chan, S. Deng, Inherent correlation between the total output cooling capacity and equipment sensible heat ratio of a direct expansion air conditioning system under variable-speed operation (XXG SMD SHR DX AC unit), Applied Thermal Engineering, vol. 30, no. 13, pp. 1601-1607, 2010.

[32] N. Li, L. Xia, S. Deng, X. Xu, M. Chan, Dynamic modeling and control of a direct expansion air conditioning system using artificial neural network, Applied Energy, vol. 91, no. 1, pp. 290-300, 2012.

[33] F. Muñoz, E.N. Sanchez, Y. Xia, S. Deng, Real-time neural inverse optimal control for indoor air temperature and humidity in a direct expansion (DX) air conditioning (A/C) system, International Journal of Refrigeration, vol. 79, pp. 196-206, 2017.

[34] H. Yan, Y. Xia, S. Deng, Simulation study on a three-evaporator air conditioning system for simultaneous indoor air temperature and humidity control, Applied Energy, vol. 207, pp. 294-304, 2017.

[35] H. Yan, Y. Xia, X. Xu, S. Deng, Inherent operational characteristics aided fuzzy logic controller for a variable speed direct expansion air conditioning system for simultaneous indoor air temperature and humidity control, Energy and Buildings, vol. 158, pp. 558-568, 2018.

[36] Y. Zhu, X. Jin, X. Fang, Z. Du, Optimal control of combined air conditioning system with variable refrigerant flow and variable air volume for energy saving, International Journal of Refrigeration, vol. 42, pp. 14-25, 2014.

[37] Y. Zhu, X. Jin, Z. Du, X. Fang, B. Fan, Control and energy simulation of variable refrigerant flow air conditioning system combined with outdoor air processing unit, Applied Thermal Engineering, vol. 64, pp. 385-395, 2014.

[38] S.Y. Lin, S.C. Chiu, W.Y. Chen, Simple automatic supervisory control system for office building based on energy-saving decoupling indoor comfort control, Energy and Buildings, vol. 86, pp. 7-15, 2015.

[39] K. Gladyszewska-Fiedoruk, Correlations of air humidity and carbon dioxide concentration in the kindergarten, Energy and Buildings, vol. 62, pp. 45-50, 2013.

[40] A. Asif, M. Zeeshan, M. Jahanzaib, Indoor temperature, relative humidity and $\mathrm{CO}_{2}$ levels assessment in academic buildings with different heating, ventilation and air-conditioning systems, Building and Environment, vol. 133, pp. 83-90, 2018.

[41] J. Kim, T. Hong, J. Jeong, M. Lee, M. Lee, K. Jeong, C. Koo, J. Jeong, Establishment of an optimal occupant behavior considering the energy consumption and indoor environmental quality by region, Applied Energy, vol. 204, pp. 1431-1443, 2017.

[42] J. Mei, X. Xia, Energy-efficient predictive control of indoor thermal comfort and air quality in a direct expansion air conditioning system, Applied Energy, vol. 195, pp. 439-452, 2017.

[43] G.Y. Yun, J. Choi, J.T. Kim, Energy performance of direct expansion air handling unit in office buildings, Energy and Buildings, vol. 77, pp. 425-431, 2014

[44] Q. Qi, S. Deng, Multivariable control-oriented modeling of a direct expansion (DX) air conditioning (A/C) system, International Journal of Refrigeration, vol. 31, no. 5, pp. 841-849, 2008.

[45] S. Wang, X. Jin, Model-based optimal control of VAV air-conditioning system using genetic algorithm, Building and Environment, vol. 35, pp. 471-487, 2000.

[46] W. Chen, S. Deng, Development of a dynamic model for a DX VAV air conditioning system, Energy Conversion and Management, vol. 47, no. 48-49, pp. 2900-2924, 2006.

[47] P.O. Fanger, Thermal Comfort: Analysis and Applications in Environmental Engineering, Copenhagen, Denmark: Danish Technical Press, 1972.

[48] M.S. Owen, 2009 ASHRAE Handbook-Fundamentals, ASHRAE, SI Edition, 2009.

[49] K. Cena, J. Clark, Bioengineering, Thermal Physiology and Comfort, Studies in Environmental Science 10, Elsevier Scientific Publishing Company, 1981.

[50] N. Djongyang, R. Tchinda, D. Njomo, Thermal comfort: A review paper, Renewable and Sustainable Energy Reviews, vol. 14, no. 9, pp. 2626-2640, 2010.

[51] S.R. West, J.K. Ward, J. Wall, Trial results from a model predictive control and optimisation system for commercial building HVAC, Energy and Buildings, vol. 72, pp. 271-279, 2014.

[52] V. Vakiloroaya, B. Samali, and K. Pishghadam, Investigation of energy-efficient strategy for direct expansion air-cooled air conditioning systems, Applied Thermal Engineering, vol. 66, no. 1-2, pp. 84-93, 2014.

[53] X. Xia, J. Zhang, and A. Elaiw, An application of model predictive control to the dynamic economic dispatch of power generation, Control Engineering Practice, vol. 19, pp. 638-648, 2011.

[54] J. Zhang, X. Xia, A model predictive control approach to the periodic implementation of the solutions of the optimal dynamic resource allocation problem, Automatica, vol. 47, no. 2, pp. 358-362, 2011.

[55] ASHRAE, Handbook of HVAC Applications, American Society of Heating, Refrigerating and Air Conditioning Engineers, Atlanta, GA, USA, 2003. 